\title{
Determination of Oxygen Transport Properties from Flux and Driving Force Measurements
}

\author{
Dalslet, Bjarke Thomas; Søgaard, Martin; Hendriksen, Peter Vang
}

Published in:

Journal of The Electrochemical Society

Link to article, DOI:

$10.1149 / 1.2789806$

Publication date:

2007

Document Version

Publisher's PDF, also known as Version of record

Link back to DTU Orbit

Citation (APA):

Dalslet, B. T., Søgaard, M., \& Hendriksen, P. V. (2007). Determination of Oxygen Transport Properties from Flux and Driving Force Measurements. Journal of The Electrochemical Society, 154(12), B1276-B1287. https://doi.org/10.1149/1.2789806

\section{General rights}

Copyright and moral rights for the publications made accessible in the public portal are retained by the authors and/or other copyright owners and it is a condition of accessing publications that users recognise and abide by the legal requirements associated with these rights.

- Users may download and print one copy of any publication from the public portal for the purpose of private study or research.

- You may not further distribute the material or use it for any profit-making activity or commercial gain

- You may freely distribute the URL identifying the publication in the public portal 


\title{
Determination of Oxygen Transport Properties from Flux and Driving Force Measurements
}

\author{
Bjarke Thomas Dalslet, ${ }^{\mathrm{z}}$ Martin Søgaard, and Peter Vang Hendriksen
}

Risф National Laboratory, Roskilde 4000, Denmark

\begin{abstract}
We demonstrate that an electrolyte probe can be used to measure the difference in oxygen chemical potential across the surface, when an oxygen flux is forced through an oxygen permeable membrane disk. The oxygen flux as well as the total oxygen chemical potential difference is carefully controlled by an oxygen pump. The developed method is tested on a $\left(\mathrm{La}_{0.6} \mathrm{Sr}_{0.4}\right)_{0.99} \mathrm{Co}_{0.2} \mathrm{Fe}_{0.8} \mathrm{O}_{3-\delta}$ membrane. An $\mathrm{La}_{0.75} \mathrm{Sr}_{0.25} \mathrm{MnO}_{3} / \mathrm{Y}_{0.16} \mathrm{Zr}_{0.84} \mathrm{O}_{1.92} / \mathrm{La}_{0.75} \mathrm{Sr}_{0.25} \mathrm{MnO}_{3}$ oxygen pump was attached to one side of the membrane. A conical $\mathrm{Ce}_{0.9} \mathrm{Gd}_{0.1} \mathrm{O}_{1.95}$ (CG10) electrolyte probe was pressed against the other side of the membrane. The voltage difference between the base and the tip of the CG10 probe was recorded with an applied oxygen flux through the membrane. This voltage was used to extract precise values of the surface exchange rate constant, $k_{\mathrm{O}}$. Using these values of $k_{\mathrm{O}}$, the vacancy diffusion factor, $D_{\mathrm{v}}^{0}$, could be extracted from data of the flux and the oxygen chemical potential difference across the membrane measured with the oxygen pump. Furthermore, upon a gas change, the transient voltage signals of the oxygen pump and the probe could be fitted to give values of $D_{\mathrm{v}}^{0}$ and $k_{\mathrm{O}}$.

(C) 2007 The Electrochemical Society. [DOI: 10.1149/1.2789806] All rights reserved.
\end{abstract}

Manuscript submitted June 18, 2007; revised manuscript received August 29, 2007. Available electronically October $12,2007$.

Mixed ionic and electronic conductors (MIECs) are interesting materials for cathodes in solid oxide fuel cells. ${ }^{1,2}$ Other uses of MIECs exist in the field of controlled oxidation, oxygen production, or reactors for partial oxidation of methane to synthesis gas. ${ }^{3,4}$ Current research focuses on identifying materials combining good mechanical, catalytic, and oxygen permeation properties. To rationalize this process, accurate measurement methods and models are needed to evaluate the catalytic properties and the ionic and electronic transport parameters. Numerous studies using methods like conductivity relaxation $^{5-8}$ and isotopic exchange ${ }^{9,10}$ characterize both the ionic exchange process on the surface of the MIEC and the bulk transport of ions, based on the fitting of a single transient response. Other studies have investigated the oxygen permeability of membranes positioned between gas flows of different oxygen chemical potential. ${ }^{11-13}$ These conventional methods lack precision, as the surface exchange process and the bulk transport process can be difficult or impossible to distinguish from each other. Several studies ${ }^{1,8,14,15}$ show, for instance, the difficulty in measuring the surface exchange rate of perovskite MIEC samples thicker than $0.1 \mathrm{~mm}$ at high temperature and oxygen partial pressure, where the surface exchange reaction is so fast that transport is completely dominated by the bulk. A possible solution is to investigate samples of different geometry (thick membranes to determine the bulk transport, thin films for surface sensitivity). This is, however, a cumbersome and not always satisfactory approach as the relaxations of thin films are very fast at high temperatures. Furthermore, the surface properties of thin films are not necessarily the same as those of bulk samples as they depend heavily on the substrate and preparation method. ${ }^{16}$

The objective of this study is to demonstrate a setup with improved measurement precision, combining a surface sensitive electrolyte probe and an oxygen pump. First, the required equipment is detailed; second, the basic theory of electrolyte sensors and mixed conductors is treated; third, the models needed to interpret the measurements are described; and finally, details of the data treatment and minor corrections will be discussed. The transport properties of the well characterized perovskite MIEC $\left(\mathrm{La}_{0.6} \mathrm{Sr}_{0.4}\right)_{0.99} \mathrm{Co}_{0.2} \mathrm{Fe}_{0.8} \mathrm{O}_{3-\delta}$ (LSCF) measured by the method are then presented, followed by a discussion of possible misinterpretations and inaccuracies of the models.

Oxygen pumps, i.e., electrically controlled electrochemical cells, have frequently been used to measure oxygen fluxes with high precision in titration and permeation studies. ${ }^{1 \uparrow-20}$ In this study, the oxygen pump is used to measure the oxygen flux passing through a membrane; as the flux is directly proportional to the electronic cur-

${ }^{\mathrm{z}}$ E-mail: bjarkehingrumme@ hotmail.com rent applied between the pumping electrodes, the oxygen flux can be measured with very high accuracy. Furthermore, a set of reference electrodes on the pump can be used to measure the oxygen chemical potential, $\mu_{\mathrm{O}_{2}}$, in situ. Electrolyte probes have been used to measure properties of oxygen ion conducting materials by, e.g., Fouletier et $\mathrm{al}^{21}$ and Wiemhöfer et al. ${ }^{22}$ Their potential for measuring the surface exchange kinetics was proposed by Bouwmeester. ${ }^{1}$ The electrolyte probe in this study measures the difference in chemical potential of oxygen across the membrane surface as a voltage. The combination of a local probe and a precise flux measurement allows the precise determination of both the bulk transport and surface exchange parameters while only applying a small steady state oxygen chemical potential difference across the membrane ensuring an almost homogenous oxide ion distribution. Furthermore, relaxation measurements are made by application of a stepwise gas composition change on one side of the membrane. This causes a relaxation of the oxide ion distribution in the membrane. The resulting transient response in the driving force gradients provides another experimental route to determine the bulk transport and surface exchange parameters.

\section{Experimental}

Sample preparation.- LSCF powder was prepared by the glycine pyrolysis process. ${ }^{23}$ The powder was calcined at $900{ }^{\circ} \mathrm{C}$ for $12 \mathrm{~h}$, and ballmilled using $5 \times 5 \mathrm{~mm}$ cylindric $\mathrm{ZrO}_{2}$ balls in a $500 \mathrm{~mL}$ polyethylene container with ethanol for $24 \mathrm{~h}$ at $200 \mathrm{rpm}$. A flat cylindric membrane was shaped from this powder using a uniaxial pressure of $70 \mathrm{MPa}$. This membrane was isostatically compressed in an evacuated latex container suspended in water at a pressure up to $325 \mathrm{MPa}$. The membrane was sintered at $1300^{\circ} \mathrm{C}$ for $12 \mathrm{~h}$. The sintered membrane was polished with $\mathrm{SiC}$ polishing sheets and diamond suspensions (particle size down to $1 \mu \mathrm{m}$ ). The sintered and polished membrane had a diameter of $20.3 \pm 0.1 \mathrm{~mm}$, a thickness of $2.253 \pm 0.005 \mathrm{~mm}$ and a density of $5965 \mathrm{~kg} \mathrm{~m}^{-3}(95 \%$ of bulk). X-ray diffraction revealed a single phase hexagonal perovskite with cell parameters $a=5.487 \AA$ and $c=13.48 \AA$.

Setup and measurement procedure.- The experimental setup is shown in Fig. 1. The MIEC membrane is placed between two $300 \mu \mathrm{m}$ thick gold sealing rings. The inner diameter of the gold rings is $14 \mathrm{~mm}$ and defines the perimeter of the active surface of the membrane. The closed compartment is defined by the membrane, the lower gold sealing ring and an $\mathrm{Y}_{0.16} \mathrm{Zr}_{0.84} \mathrm{O}_{1.92}$ (YSZ) oxygen pump. Two pairs of electrodes are painted on the oxygen pump. Each pair has one electrode in the closed compartment, and one electrode in the reference compartment, which is flushed with an air flow $\left(>2.10^{-6} \mathrm{~m}^{3} / \mathrm{s}\right.$ or $120 \mathrm{~mL} / \mathrm{min}$ at ambient conditions). The 


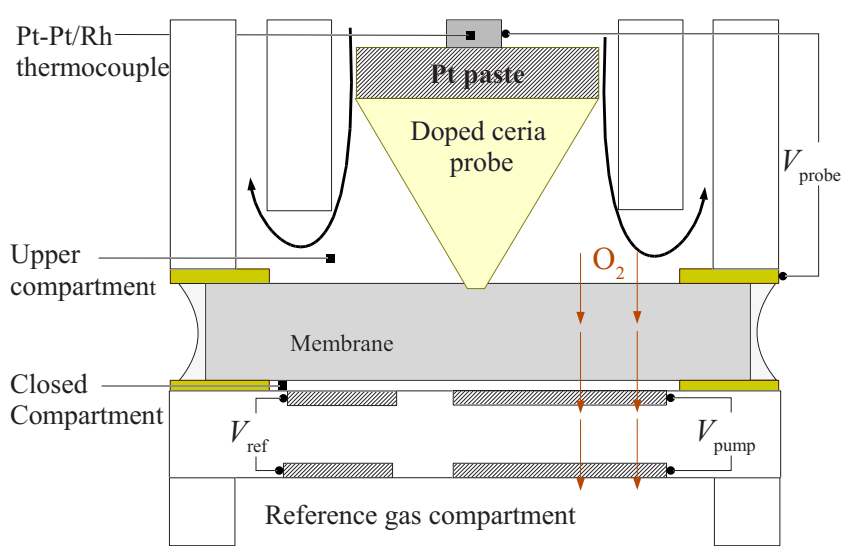

Figure 1. (Color online) The measurement setup.

pumping electrode pair is made of a mixture of porous $50 \% \mathrm{YSZ}$ $+50 \% \mathrm{La}_{0.75} \mathrm{Sr}_{0.25} \mathrm{MnO}_{3}$ with porous $\mathrm{Pt}$ as current collector and is used to pump oxygen in and out of the closed compartment. The reference electrode pair is made of porous $\mathrm{Pt}$ (sintered Ferro $\mathrm{Pt}$ paste), and is used to measure the difference in oxygen chemical potential between the closed compartment and the reference compartment. The circumference of the membrane is sealed using a glass seal. Above the membrane an alumina cylinder defines an upper compartment. Two concentric alumina pipes terminates in the upper compartment. The inner pipe feeds gas (the "flow gas") to the upper compartment while the outer pipe transports the exhaust gas to a Pt $|Y S Z| \mathrm{Pt} p_{\mathrm{O} 2}$ sensor. The gas flow through the upper compartment is $1.67 \times 10^{-6} \mathrm{~m}^{3} / \mathrm{s}(100 \mathrm{~mL} / \mathrm{min}$ measured at ambient conditions) of air diluted with $\mathrm{N}_{2}$. Inside the inner pipe a spring loaded thermocouple applies an electrical contact and a downward mechanical force to a pointed electrolyte probe in contact with the membrane surface. The pointed probe was made from $\mathrm{Ce}_{0.9} \mathrm{Gd}_{0.1} \mathrm{O}_{1.95}$ (CG10). CG10 was selected over YSZ to avoid $\mathrm{SrZrO}_{3}$ formation at the probe tip. A cylinder was shaped using an uniaxial pressure of $70 \mathrm{MPa}$. It was then isostatically compressed in an evacuated latex container suspended in water at a pressure up to $325 \mathrm{MPa}$. After sintering at $1323 \mathrm{~K}$ the CG10 cylinder was mechanically sharpened and resintered at $1873 \mathrm{~K}$. All electrical contacts were made using platinum and gold wires. A Solartron $1250 / 1286$ setup was used as a programmable current source with a Keithley 2700 multimeter/data collector.
Defect chemistry and transport properties of LSCF.- In this section, the defect chemistry and transport properties of the test material, LSCF, are described. Two models for interpretation of steady state and relaxation measurements, respectively, are presented.

Defect chemistry.- The release and incorporation of oxygen in LSCF can be written in the Kröger-Vink notation

$$
2 \mathrm{O}_{\mathrm{O}}^{\mathrm{X}} \leftrightarrows \mathrm{O}_{2}^{\mathrm{gas}}+2 \mathrm{~V}_{\mathrm{O}}^{*}+4 \mathrm{e}^{\prime}
$$

At equilibrium the chemical potential of oxygen, $\mu_{\mathrm{O}_{2}}$ is the same in the gas and solid phase. This allows us to label the state of the LSCF MIEC with the state of the gas with which it is in equilibrium, and vice versa. The chemical potential of oxygen, $\mu_{\mathrm{O}_{2}}^{\mathrm{MIEC}}$, in a MIEC in equilibrium with a gas with a given chemical potential of oxygen $\mu_{\mathrm{O}_{2}}^{\text {eq.gas }}$ can then be defined as

$$
\mu_{\mathrm{O}_{2}}^{\mathrm{MIEC}}=\mu_{\mathrm{O}_{2}}^{\text {gas }}=\mu_{\mathrm{O}_{2}}^{\ominus}+R T \ln \left(p_{\mathrm{O}_{2}}^{\text {eq.gas }} / p_{\mathrm{O}_{2}}^{\ominus}\right)
$$

where $R$ is the gas constant and $T$ is the temperature; $p_{\mathrm{O}_{2}}^{\text {eq.gas }}$ and $p_{\mathrm{O}_{2}}^{\ominus}$ are the oxygen partial pressures of the equilibrium and standard gas, respectively. The oxygen chemical potential of the selected standard gas $\mu_{\mathrm{O}_{2}}^{\ominus}$ can be calculated using the IUPAC standards, ${ }^{24}$ see Appendix A. Likewise, the equivalent oxide concentration in the gas, $C_{\mathrm{O}}^{\text {gas }}$, is defined as the oxide concentration $C_{\mathrm{O}}^{\mathrm{MIEC}}$ in the MIEC with which it is in equilibrium. A difference in $\mu_{\mathrm{O}_{2}}^{\mathrm{MIEC}}, \Delta \mu_{\mathrm{O}_{2}}^{\mathrm{MIEC}}$ can then (for small differences) be written in terms of a difference in $C_{\mathrm{O}}^{\mathrm{MIEC}}$, $\Delta C_{\mathrm{O}}^{\mathrm{MIEC}}$

$$
\Delta \mu_{\mathrm{O}_{2}}^{\mathrm{MIEC}}=R T \Delta \ln p_{\mathrm{O}_{2}}^{\text {eq.gas }} \simeq R T \frac{\Delta C_{\mathrm{O}}^{\mathrm{MIEC}}}{C_{\mathrm{O}}^{\mathrm{MIEC}}} \frac{\partial \ln p_{\mathrm{O}_{2}}^{\text {eq.gas }}}{\partial \ln C_{\mathrm{O}}^{\mathrm{MIEC}}}=2 R T \frac{\Delta C_{\mathrm{O}}^{\mathrm{MIEC}}}{C_{\mathrm{O}}^{\mathrm{MIEC}}} \gamma
$$

where $\gamma=\partial \ln p_{\mathrm{O}_{2}}^{\text {eq.gas }} / 2 \partial \ln C_{\mathrm{O}}^{\mathrm{MIEC}}$ is the thermodynamical factor.

The equilibrium relation between $\mu_{\mathrm{O}_{2}}$ and $C_{\mathrm{O}}^{\mathrm{MIEC}}$ for a given $p_{\mathrm{O}_{2}}^{\text {eq.gas }}$ has been determined using thermogravimetry and coulometric titration. Thermogravimetry is a widely used method. coulometric titration measures $\mu_{\mathrm{O}_{2}}^{\text {MIEC }}$ as function of oxygen pumped, via an oxygen pump, into a sealed chamber with a powder sample. A detailed description of this method is beyond the scope of this paper, and we refer to the paper by Zachau-Christiansen et al. ${ }^{17}$ The values for the thermodynamic factor, $\gamma$, and oxygen nonstoichiometry parameter, $\delta$, are reproduced in Fig. 2. Further details will be made available in a future publication.

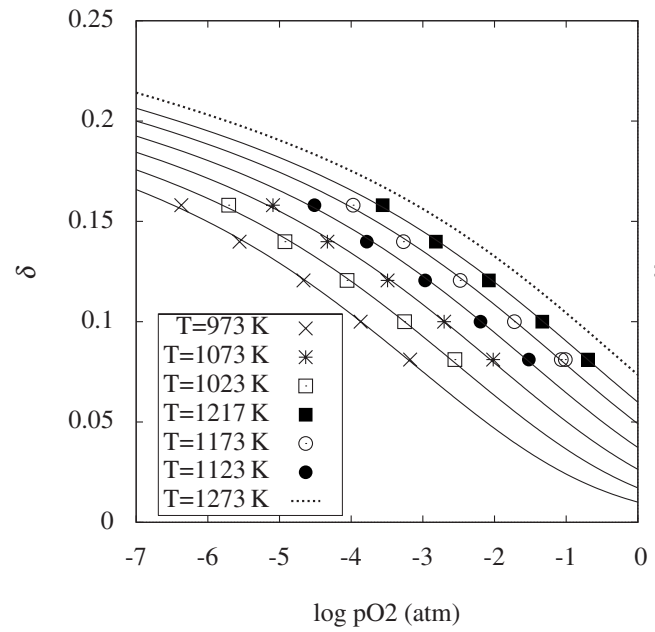

a)

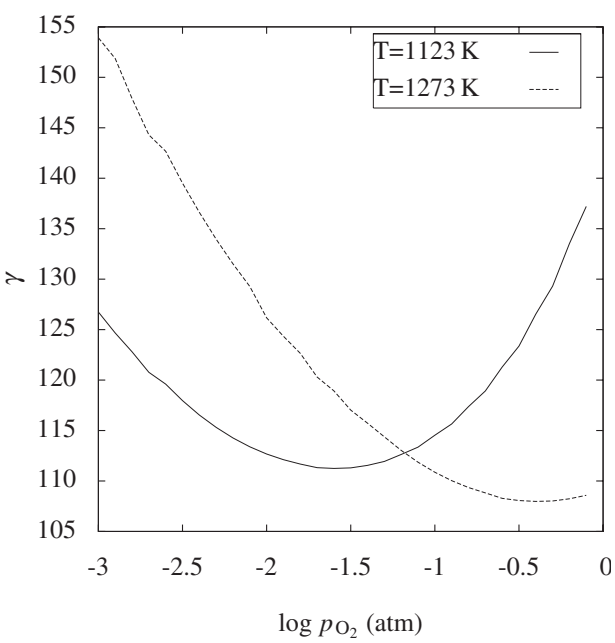

b)
Figure 2. (a) $\delta$ as function of $p_{\mathrm{O}_{2}}$. Points are measured values and the lines are from a model fit. (b) The thermodynamic factor, $\gamma$, as function of $p_{\mathrm{O}_{2}}$ derived from the model lines in (a). 


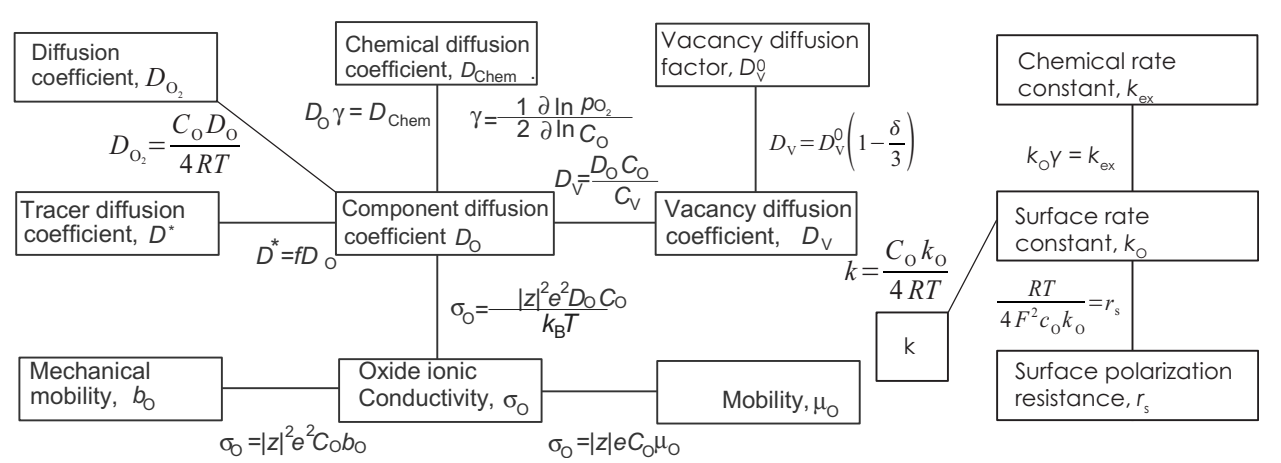

Figure 3. Relations between transport parameters in LSCF: $f$ is the correlation factor $(0.69$ for perovskites as LSCF), $\gamma$ is the thermodynamic enhancement factor, $z$ is the charge number of the ionic species, i.e., -2 for $\mathrm{O}^{2-}, k_{B}$ is the Boltzmann constant, $e$ is the electronic charge, and $\delta$ is the number of vacancies per formula unit. $C_{\mathrm{O}}$ is the concentration of oxide ions. $C_{\mathrm{V}}$ is the concentration of oxide vacancies. $R$ is the gas constant and $T$ is the temperature.
Transport properties. - In this study different parameters will be used to describe the oxygen transport in the bulk and across the surface. These parameters are described by Maier ${ }^{25}$ and in the textbooks by Tilley ${ }^{26}$ or Gellings and Bouwmeester. ${ }^{1}$ In LSCF local electroneutrality causes the transport of electrons $\left(\mathrm{e}^{-}\right)$and oxygen ions $\left(\mathrm{O}^{2-}\right)$ to be coupled. In LSCF, the ionic conductivity is controlling the transport of both electrons and ions as the electronic conductivity is much larger than the ionic conductivity. In the absence of external electrical fields, we are free to define the diffusing species in the material as "oxygen," $\mathrm{O}_{2}$, consisting of two oxide ions $\mathrm{O}^{2-}$ and four electron holes. From Gellings and Bouwmeester ${ }^{1}$

$$
j_{\mathrm{O}_{2}}=-\frac{1}{4^{2} F^{2}} \frac{\sigma_{\mathrm{e}} \sigma_{\mathrm{O}}}{\sigma_{\mathrm{e}}+\sigma_{\mathrm{O}}} \nabla \mu_{\mathrm{O}_{2}}^{\mathrm{MIEC}} \simeq-D_{\mathrm{O}_{2}} \nabla \mu_{\mathrm{O}_{2}}^{\mathrm{MIEC}}, \quad D_{\mathrm{O}_{2}}=\frac{\sigma_{\mathrm{O}}}{4^{2} F^{2}}
$$

where $F$ is the Faraday constant, $j_{\mathrm{O}_{2}}$ is the oxygen flux, $\sigma_{\mathrm{e}}$ is the electronic conductivity, and $\sigma_{\mathrm{O}}$ is the oxide ion conductivity. $D_{\mathrm{O}_{2}}$ is the diffusion coefficient and is defined under the assumption (true for LSCF) that $\sigma_{\mathrm{O}} \ll \sigma_{\mathrm{e}}$. Combining Eq. 3 with Eq. 4 we get Ficks first law of diffusion

$$
j_{\mathrm{O}_{2}}=-\frac{D_{\text {chem }}}{2} \nabla C_{\mathrm{O}}^{\mathrm{MIEC}}, \quad D_{\text {chem }}=\frac{4 \gamma R T}{C_{\mathrm{O}}^{\mathrm{MIEC}}} D_{\mathrm{O}_{2}}
$$

where $D_{\text {chem }}$ is the chemical diffusion coefficient of oxide ions. From $D_{\text {chem }}$ we obtain the oxygen atom self-diffusion coefficient $D_{\mathrm{O}}$ as $D_{\text {chem }} \gamma^{-1}$. As most of the oxide sites in the structure are occupied, the diffusion of oxide ions will be controlled by the number of oxide vacancy sites available. For small vacancy concentrations the transport equation becomes

$$
\begin{gathered}
j_{\mathrm{O}_{2}}=\frac{\gamma \mathrm{v}}{2} D_{\mathrm{v}}^{0}\left(1-\frac{\delta}{3}\right) \nabla C_{\mathrm{V}}, \quad D_{\mathrm{v}}^{0}=\frac{4 R T}{C_{\mathrm{V}}\left(1-\frac{\delta}{3}\right)} D_{\mathrm{O}_{2}} \\
\gamma_{\mathrm{V}}=\gamma \frac{C_{\mathrm{V}}}{C_{\mathrm{O}}^{\mathrm{MIEC}}}
\end{gathered}
$$

where $D_{\mathrm{v}}^{0}$ is the vacancy diffusion factor, $C_{\mathrm{V}}$ is the vacancy concentration, and $\gamma_{\mathrm{V}}$ is the thermodynamic factor associated with the oxygen vacancies. The term $(1-\delta / 3)$ was proposed by Lankhorst ${ }^{14}$ because a vacancy cannot diffuse to a vacant oxide site. We expect that $D_{\mathrm{v}}^{0}$ is independent of $C_{\mathrm{V}}$ apart from second order effects (such as $C_{\mathrm{V}}$ influencing the crystal structure or immobilization of vacancies due to ordering). When interpreting our measurements $D_{\mathrm{v}}^{0}$ will therefore be used as a fitting parameter.

When the surface is brought out of equilibrium with the surrounding atmosphere, a step in $\mu_{\mathrm{O}_{2}}, \Delta \mu_{\mathrm{O}_{2}}$, exists at the surface. Assuming a linear response of the flux to the step in $\mu_{\mathrm{O}_{2}}$ we can define a surface exchange coefficient, $k$, and an equivalent surface resistance $r_{\mathrm{s}}$

$$
j_{\mathrm{O}_{2}}=-k \Delta \mu_{\mathrm{O}_{2}}=-\frac{1}{4^{2} F^{2} r_{\mathrm{s}}} \Delta \mu_{\mathrm{O}_{2}}
$$

The relations between the different transport parameters are summarized in Fig. 3.

Steady state model. - To fit data recorded during steady state permeation measurements a one-dimensional numerical model based on the Wagner equation ${ }^{27}$ combined with oxygen exchange at the surface is used. The Wagner equation is obtained from integration of Eq. 4

$$
j_{\mathrm{O}_{2}}=-\frac{1}{4^{2} F^{2} L} \int_{\mu_{\mathrm{O}_{2}}^{\prime}}^{\mu_{\mathrm{O}_{2}}^{\prime \prime}} \frac{\sigma_{\mathrm{e}} \sigma_{\mathrm{O}}}{\sigma_{\mathrm{e}}+\sigma_{\mathrm{O}}} d \mu_{\mathrm{O}_{2}}
$$

where $\mu_{\mathrm{O}_{2}}^{\prime}$ and $\mu_{\mathrm{O}_{2}}^{\prime \prime}$ are the chemical potentials of oxygen at each interface (just inside the bulk, see Fig. 4).

The $\mu_{\mathrm{O}_{2}}$ profile in Fig. 5 has been calculated by a combination of Eq. 7 at the surfaces and Eq. 8 in the bulk. The calculation was done with $i_{\text {pump }}=-100 \mathrm{~A} / \mathrm{m}^{2}$ and all material properties as determined for LSCF at $T=1248 \mathrm{~K}$ and $p_{\mathrm{O}_{2}}=4 \mathrm{kPa}$. The vertical parts are the discrete jumps in $\mu_{\mathrm{O}_{2}}$ at the surfaces, and the apparently linear part is in the bulk. The linearity is achieved as very small gradients in $\mu_{\mathrm{O}_{2}}$ are applied as the oxygen pump allows very precise control of the oxygen flux. The need for a large signal/noise ratio requires a

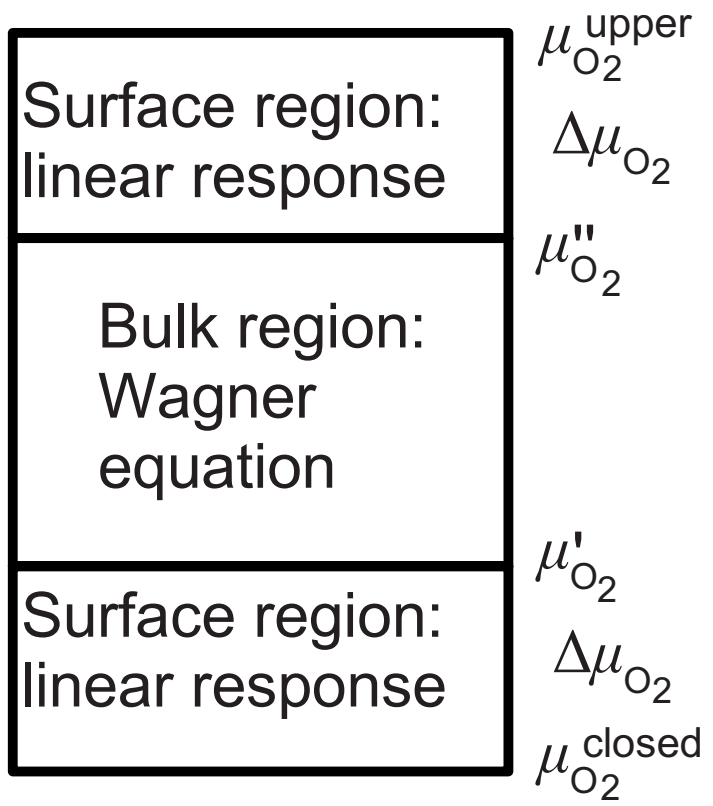

Figure 4. Sketch of the model used for analysis of steady state permeation measurements. 


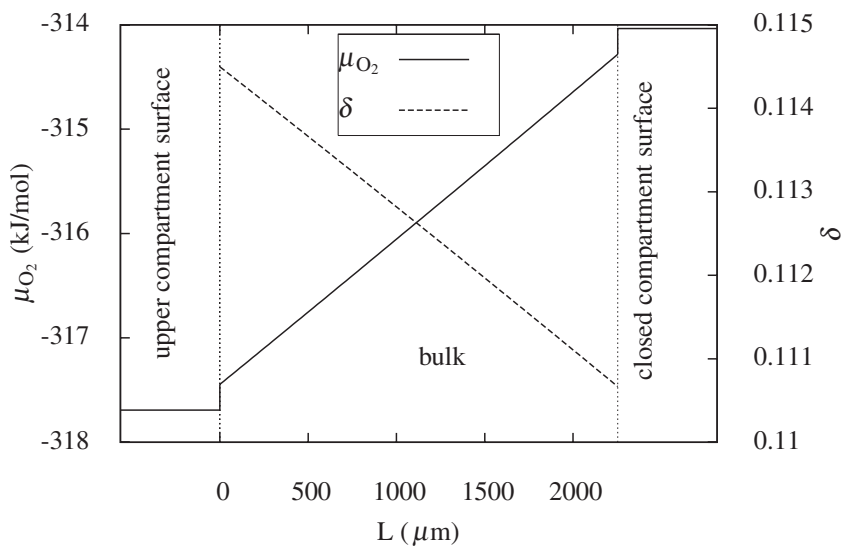

Figure 5. An example of the chemical potential profile, and the $\delta$ value of the membrane in the experiment shown in Fig. 9 calculated using the steady state model.

current density of more than $10 \mathrm{~A} / \mathrm{m}^{2}$, but Fig. 5 shows that even at $i_{\text {pump }}=-100 \mathrm{~A} / \mathrm{m}^{2}\left(I_{\text {pump }}=15 \mathrm{~mA}\right)$ only a very small variation in $\delta$ is imposed, and the transport parameters are therefore almost constant throughout the membrane.

The gold seals act as apertures for the surface exchange (see Fig. 1) but the membrane cross section is wider than these apertures, resulting in an overestimation of $D_{\mathrm{v}}^{0}$. $D_{\mathrm{v}}^{0}$ can be corrected by multiplying with a membrane geometry dependent factor $f_{\mathrm{c}}$ (for the membrane of this study it has a value of 0.93). ${ }^{28}$

Relaxation model.- When changing the $p_{\mathrm{O}_{2}}$ of the flow gas in the upper compartment the membrane will adjust its $\delta$ value to the value of $\mu_{\mathrm{O}_{2}}$. This relaxation can be fitted with an appropriate model. When the membrane is not in steady state, the time dependence of $\mu_{\mathrm{O}_{2}}^{\mathrm{MIEC}}$ will be governed by conservation of mass

$$
\frac{\partial C_{\mathrm{O}}^{\mathrm{MIEC}}}{\partial t}=\nabla \cdot \mathbf{j}_{\mathrm{O}}
$$

where $t$ is the time. Combining with Eq. 3 we get

$$
\frac{\partial \mu_{\mathrm{O}_{2}}^{\mathrm{MIEC}}}{\partial t}=2 \frac{2 R T \gamma}{C_{\mathrm{O}}^{\mathrm{MIEC}}} \nabla \cdot \mathbf{j}_{\mathrm{O}_{2}}
$$

Equations 4, 7, and 10 are solved using an iterative algorithm in a cylindrical finite element mesh. The finite element mesh consists of 20 segments in the longitudinal dimension and ten in the radial dimension. The model geometry and boundary conditions are outlined in Fig. 6.

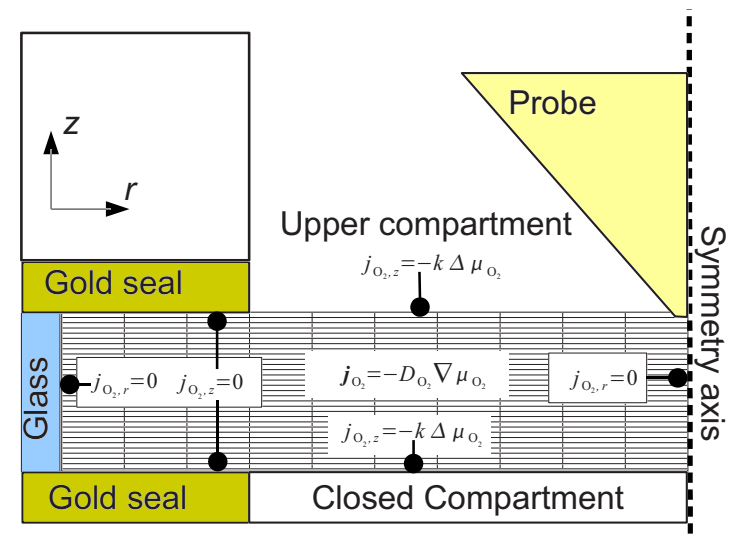

Figure 6. (Color online) Sketch of the model used for analysis of relaxation measurements.
When fitting the relaxation data, $D_{\mathrm{v}}^{0}$ is used as the fitting parameter; $D$ is calculated from $D_{\mathrm{v}}^{0}$ for each spatial segment of the membrane. $D_{\mathrm{v}}^{0}$ is assumed constant for the entire membrane.

Measurements using an oxygen pump and an electrolyte probe.- In this section the basic principle of using electrolytes to measure chemical potential differences, and the operation principle of the oxygen pump, is described. An area specific conductance of the membrane is introduced and a few necessary corrections are treated. Finally, the same principle is used to give an interpretation of the signal from an electrolyte probe along with a few corrections. Oxygen chemical potential measurement.- The basic principle behind both the probe and the oxygen pump is using oxide conducting electrolytes to measure differences in the chemical potential of oxygen. An oxide conducting electrolyte placed between two external phases with different oxygen chemical potential will approach an equilibrium between the oxide or oxygen in the two external phases and the oxide in the electrolyte surfaces. The relationship, at equilibrium, between the oxygen activity of the external phases and cell voltage, as measured between electrodes placed on the two interfaces, will be

$$
\mu_{\mathrm{O}_{2}}^{\prime}-\mu_{\mathrm{O}_{2}}^{\prime \prime}=4 F V_{\text {ele }}
$$

where $\mu_{\mathrm{O}_{2}}^{\prime}$ and $\mu_{\mathrm{O}_{2}}^{\prime \prime}$ are the oxygen chemical potential in each of the external phases, and $V_{\text {ele }}$ is the voltage between the two electrolyte|external phase interfaces.

The oxygen pump.- - The YSZ oxygen pump is an electrochemical cell with a YSZ electrolyte. It is assumed that the following reaction takes place at the pumping and reference electrodes

$$
\mathrm{O}_{2}^{\text {gas }}+4 \mathrm{e}_{\text {ele }}^{-} \leftrightarrows 2 \mathrm{O}_{\text {YSZ }}^{2-}
$$

Combining Eq. 2 and 11, the Nernst equation governing the relationship between oxygen activity and cell voltage will be

$$
p_{\mathrm{O}_{2}}^{\text {gas }}=p_{\mathrm{O}_{2}}^{\text {ref }} \exp \left(\frac{4 F V_{\text {ref }}}{R T}\right)
$$

$p_{\mathrm{O}_{2}}^{\text {gas }}$ is the oxygen partial pressure of the gas in the closed compartment, $p_{\mathrm{O}_{2}}^{\text {ref }}$ is the $p_{\mathrm{O}_{2}}$ of the gas in the reference compartment (air in these measurements) and $V_{\text {ref }}$ is the voltage between the reference electrodes. As four electrons pumped in the external circuit will correspond to one oxygen molecule passing between the electrodes of the cup, the relationship between pumping current and oxygen transfer is

$$
j_{\mathrm{O}_{2}}=\frac{I_{\text {pump }}}{4 F}
$$

where $I_{\text {pump }}$ is the pumping current.

The area specific conductance, G.- In the setup of Fig. 1 the ionic current through the membrane in steady state must equal the ionic current through the pump. In this case an area specific conductance, $G$, of the membrane can be defined as

$$
\begin{gathered}
G=\frac{i_{\text {pump }}}{\Delta V_{\text {Nernst }}}, \quad i_{\text {pump }}=I_{\text {pump }} / A_{\text {MIEC }} \\
\Delta V_{\text {Nernst }}=V_{\text {closed }}-V_{\text {upper }}=V_{\text {ref }}-V_{\text {ref }}^{0}
\end{gathered}
$$

where $i_{\text {pump }}$ is the area specific current and $A_{\text {MIEC }}$ is the exposed area of the MIEC membrane. $\Delta V_{\text {Nernst }}$ is the difference in the Nernst voltages between the gas in the upper compartment, $V_{\text {upper }}$, and the gas in the closed compartment, $V_{\text {closed, }}$, with the reference compartment gas as a common reference. $V_{\text {closed }}=V_{\text {ref }}$ are measured by the reference electrodes of the oxygen pump, with the air in the reference compartment providing the reference $\mu_{\mathrm{O}_{2}} . V_{\text {ref }}^{0}$ is measured at zero flux, where the flow gas of the upper compartment is in equilibrium with the gas in the closed compartment (i.e., $V_{\text {upper }}$ $\left.=V_{\text {closed }}\right)$. As the Nernst voltage measures the oxygen chemical potential, which is the driving force of both the bulk (Eq. 7) and the 
surface oxygen ion transport (Eq. 8), $G$ can be expected to be independent of the flux if $\sigma_{\mathrm{O}}, \sigma_{\mathrm{e}}$ and the surface resistance, $r_{s}$, are independent of the flux; this is only expected true for very small fluxes. $G$ can in this case be extracted with good accuracy as the slope of a plot of steady state values of $i_{\text {pump }}$ as function of $\Delta V_{\text {Nernst }}$. If the surface resistance is small $G$ can be converted to an ionic conductivity

$$
\sigma_{\mathrm{O}}=\frac{G f_{\mathrm{c}}}{L}
$$

by dividing with the membrane thickness $L$ and multiplying with the geometric factor $f_{c}$.

Effect of gas diffusion in the closed compartment.- In the closed compartment $V_{\text {ref }}$ is measured using two reference electrodes painted on either side of the pump. As the gas in the compartment is not stirred, an oxygen concentration gradient will be present between the reference electrode and the membrane when an ionic current runs through the membrane. The diffusion coefficient of $\mathrm{O}_{2}$ in $\mathrm{N}_{2}$ at $1273 \mathrm{~K}$ is $2.6 \times 10^{-4} \mathrm{~m}^{2} / \mathrm{s}^{29}$ As the distance between the electrode and the membrane is $0.3 \mathrm{~mm}$, the $p_{\mathrm{O}_{2}}$ difference needed to support a large $130 \mathrm{~A} / \mathrm{m}^{2}$ pumping current would be $5 \mathrm{~Pa}$. This is much smaller than the difference measured with $\Delta V_{\text {Nernst }}$ which in this case is more than $100 \mathrm{~Pa}$. The $p_{\mathrm{O}_{2}}$ gradient in the compartment is thus very small and $G$ is not affected by gas diffusion in the compartment.

Effect of permeation flux on the flow gas.- The oxygen flux through the membrane will change the $p_{\mathrm{O}_{2}}$ above the membrane. Applying a simple mass balance approach, the change in $p_{\mathrm{O}_{2}}$ will be proportional to $I_{\text {pump }}$ and inversely proportional to the volume flow of gas through the upper chamber, $\Phi_{\mathrm{f}}$. The gas flow direction can be approximated as a radial distribution spreading from the membrane center point and thus $\mu_{\mathrm{O}_{2}}$ is not homogeneous across the membrane surface. The average Nernst voltage of the gas in the upper compartment, $V^{\text {upper }}$ measured vs air is derived in Appendix B as

$$
V^{\text {upper }}=\frac{R T}{4 F}\left[\ln \left(\frac{p_{\mathrm{O}_{2}}^{\text {in }}}{p_{\mathrm{O}_{2}}^{\text {air }}}\right)+\left(\frac{p_{\mathrm{O}_{2}}^{\text {in }}}{\Delta p_{\mathrm{O}_{2}}}+1\right)\left(\ln \left(\frac{\Delta p_{\mathrm{O}_{2}}}{p_{\mathrm{O}_{2}}^{\text {in }}}+1\right)-1\right)\right]
$$

$$
\begin{gathered}
\Delta p_{\mathrm{O}_{2}}=\frac{I_{\text {pump }} R T_{\Phi_{\mathrm{f}}}}{4 F \Phi_{\mathrm{f}}} \quad \text { (steady state) } \\
\Delta p_{\mathrm{O}_{2}}=\frac{J_{\mathrm{O}_{2}} R T_{\Phi_{\mathrm{f}}}}{\Phi_{\mathrm{f}}} \quad \text { (relaxation) }
\end{gathered}
$$

where $T_{\Phi_{\mathrm{f}}}$ is the temperature at which the volume flow is measured. $p_{\mathrm{O}_{2}}^{\text {in }}$ is the $p_{\mathrm{O}_{2}}$ of the inlet gas, calculated from $V_{\text {ref }}^{0}$. The deviation of $V^{\text {upper }}$ from $V_{\text {ref }}^{0}$ results in an underestimation of $G$ in the steady state measurement. Substituting $V^{\text {upper }}$ for $V_{\text {ref }}^{0}$ in Eq. 15 gives a corrected area specific conductance $G_{c}$. In the relaxation measurements the permeation flux will cause a deviation from the usual step change of $\mu_{\mathrm{O}_{2}}$. If this deviation is not taken into account, $k$ will be underestimated.

The electrolyte probe.- The tip of the electrolyte probe is in ionic and electronic contact with the MIEC membrane; the porous platinum electrode on the other side of the probe sits in the flow gas. Assuming that equilibrium exists between the platinum and the gas and between the probe tip and the MIEC membrane, Eq. 11 and 2 states that the probe voltage, $V_{\text {probe }}$, is a direct measure of the difference in $\mu_{\mathrm{O}_{2}}$ between the inlet flow gas and MIEC membrane surface

$$
\Delta \mu_{\mathrm{O}_{2}}=\mu_{\mathrm{O}_{2}}^{\text {in }}-\mu_{\mathrm{O}_{2}}^{\mathrm{MIEC}}=4 F V_{\text {surface }}
$$

where $\mu_{\mathrm{O}_{2}}^{\text {in }}$ and $\mu_{\mathrm{O}_{2}}^{\text {MIEC }}$ are the oxygen chemical potential, of the inlet flow gas, and just inside the MIEC surface, respectively. $V_{\text {surface }}$ is

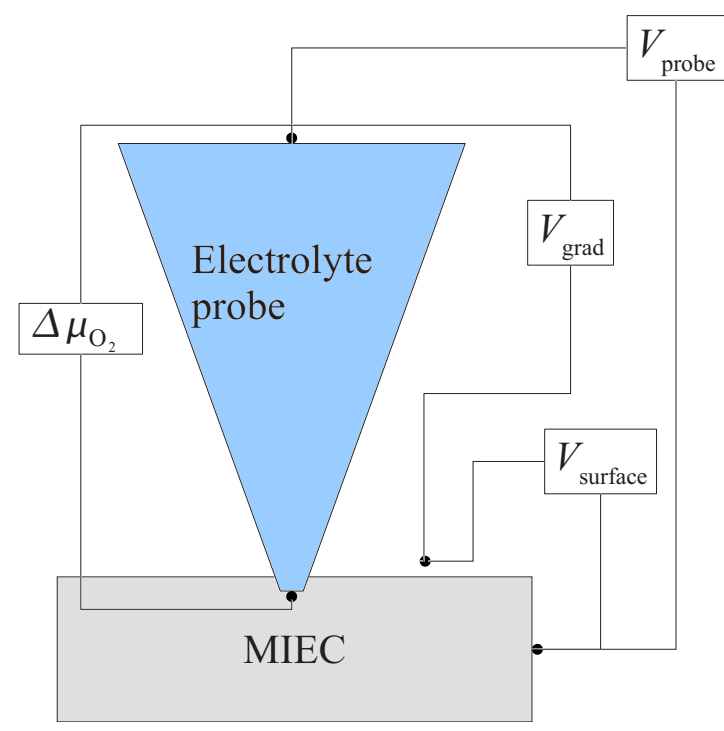

Figure 7. (Color online) A schematic of the origins of the contributions to the probe voltage.

the part of the probe voltage, $V_{\text {probe }}$, attributable to the oxygen exchange over the surface.

Apart from $V_{\text {surface }}$, there are other contributions to $V_{\text {probe }}$ when there is a flux of oxygen through the membrane surface (see Fig. 7). They can be written

$$
V_{\text {probe }}=V_{\text {surface }}+V_{\text {grad }}+\Sigma_{i} V_{i}
$$

where $V_{\text {grad }}$ is the contribution from differences in the $p_{\mathrm{O}_{2}}$ of the gas at a point just over the membrane, and the gas at the Pt electrode on the back of the probe. $\Sigma_{i} V_{i}$ is the sum of any other contributions present, such as thermoelectric voltages. $\Sigma_{i} V_{i}$ is assumed to be independent of the ionic current. While $\Sigma_{i} V_{i}$ can be the largest contribution to $V_{\text {probe }}$, it can thus be filtered out by measuring $V_{\text {probe }}$ at different currents.

$V_{\text {grad }}-V_{\text {grad }}$ is determined by a number of factors including flow geometry, gas diffusion coefficient, $T$, etc. In the next section it will be shown that $V_{\text {probe }}$ is independent of the gas diffusion coefficient. Assuming that the flow geometry is symmetric with respect to a gas flow direction reversal, $V_{\text {grad }}$ can be estimated:

The $p_{\mathrm{O}_{2}}$ of the gas close to the probe/MIEC membrane interface, $p_{\mathrm{O}_{2}}^{\text {tip }}$ is different from the $p_{\mathrm{O}_{2}}$ of the inlet gas, due to the oxygen flux through the membrane. Assuming that the flux distribution over the membrane is independent of the flow rate and $p_{\mathrm{O}_{2}}$ of the gas, $p_{\mathrm{O}_{2}}^{\text {tip }}$ can be written

$$
p_{\mathrm{O}_{2}}^{\text {tip }}=p_{\mathrm{O}_{2}}^{\text {in }}+\beta\left(p_{\mathrm{O}_{2}}^{\text {out }}-p_{\mathrm{O}_{2}}^{\text {in }}\right)
$$

where $\beta$ is a variable depending on the geometry of the setup. If the gas flow direction is reversed such that it enters via the outer pipe and exits via the inner pipe Eq. 23 becomes

$$
p_{\mathrm{O}_{2}}^{\text {tip }}=p_{\mathrm{O}_{2}}^{\text {in }}+(1-\beta)\left(p_{\mathrm{O}_{2}}^{\text {out }}-p_{\mathrm{O}_{2}}^{\text {in }}\right)
$$

$\beta$ was extracted using Eq. 23 and 24 by comparing measurements with the regular and inverted gas flow directions. It was found to be $0.09 \pm 0.02 ; p_{\mathrm{O}_{2}}^{\text {tip }}$ is thus close to $p_{\mathrm{O}_{2}}^{\text {in }}$.

$V_{\text {grad }}$ can then be calculated as

$$
V_{\text {grad }}=\frac{R T}{4 F} \ln \left(\frac{p_{\mathrm{O}_{2}}^{\text {in }}+\beta \frac{I_{\text {pump }} R T_{\Phi_{\mathrm{f}}}}{4 F \Phi_{\mathrm{f}}}}{p_{\mathrm{O}_{2}}^{\text {in }}}\right)
$$

The polarization resistance, $r_{\mathrm{s}}$, of the surface is finally calculated as 


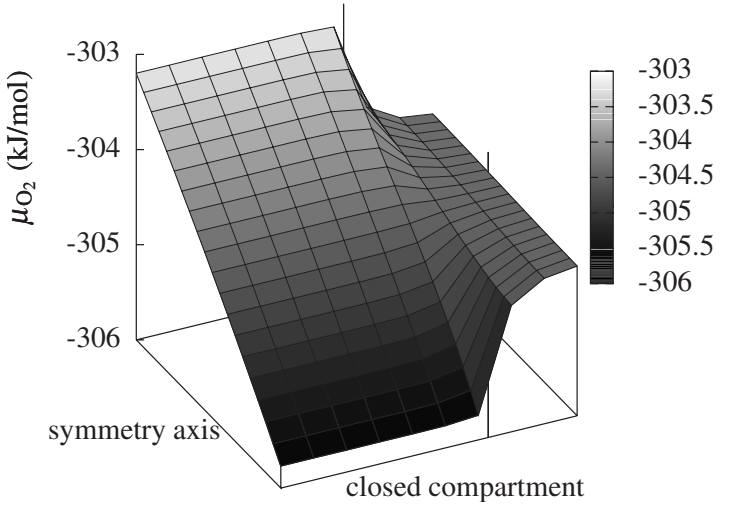

Figure 8. $\mu_{\mathrm{O}_{2}}$ in the MIEC membrane in a steady state measurement at $T$ $=1273 \mathrm{~K}$ in air. $i_{\text {pump }}=-65 \mathrm{~A} / \mathrm{m}^{2}$. Two vertical lines mark the edge of the gold seal. The total length along the symmetry axis is $2.253 \mathrm{~mm}$. The total length along the closed compartment edge is $10.15 \mathrm{~mm}$ (half the membrane diameter), with the aperture extending $7 \mathrm{~mm}$ from the symmetry axis, where the gold seal blocks the flux (see Fig. 6).

$$
r_{\mathrm{s}}=\frac{V_{\text {probe }}-V_{\text {mixing }}-\Sigma_{i} V_{i}}{i_{\text {pump }}}
$$

In the data analysis we will assume that $\Sigma_{i} V_{i}$ is independent of $i_{\text {pump }}$ and equal to $V_{\text {probe }}$ when $i_{\text {pump }}=0 . V_{\text {mixing }}$ is between 0 and $10 \%$ of $V_{\text {probe }}$ in the measurements of this study. This difference is largest when the $p_{\mathrm{O}_{2}}$ is low and when the temperature is high.

\section{Results and Discussion}

In this section the transport properties of the $\left(\mathrm{La}_{0.6} \mathrm{Sr}_{0.4}\right)_{0.99} \mathrm{Co}_{0.2} \mathrm{Fe}_{0.8} \mathrm{O}_{3-\delta}$ (LSCF) as measured by the described method are presented, including discussions of possible misinterpretations of the measured data.

Steady state measurements. - Steady state experiments are performed by applying various currents to the pump. This creates a gradient in $\mu_{\mathrm{O}_{2}}$. The calculated $\mu_{\mathrm{O}_{2}}$ in the membrane in a steady state measurement at $T=1273 \mathrm{~K}$ in air and with pumping current $i_{\text {pump }}=-65 \mathrm{~A} / \mathrm{m}^{2}$ is shown in Fig. 8 .

For each value of $T$ and $p_{\mathrm{O}_{2}}^{\text {in }}$ several different values of $i_{\text {pump }}$ were applied; $i_{\text {pump }}$ is plotted as function of the reference voltage at $T$ $=1248 \mathrm{~K}$ in a 4:1 $\mathrm{N}_{2}$ :air gas mixture (i.e., $p_{\mathrm{O}_{2}}$ about $4 \mathrm{kPa}$ ), in Fig. 9a). Negative values of $i_{\text {pump }}$ correspond to oxygen being pumped from the closed compartment to the reference compartment. Negative values of $V_{\text {ref }}$ means that the $p_{\mathrm{O}_{2}}$ in the closed compartment is lower than the $p_{\mathrm{O}_{2}}$ in the reference compartment. There is clearly a linear relation between $i_{\text {pump }}$ and $V_{\text {ref. }} G=10.11 \pm 0.03 \mathrm{kS} / \mathrm{m}^{2}$ is extracted as the slope of the linear fit. Note that the standard deviation is less than $0.1 \%$ of the measured value. Most of the $G$ measurements in this study were done with standard deviations less than $1 \%$.

In the same experiment a linear relationship between $V_{\text {probe }}$ and $i_{\text {pump }}$ is also found and shown in Fig. 9b. Positive values of $V_{\text {probe }}$ correspond to $\mu_{\mathrm{O}_{2}}$ being lower at the probe tip, than at the platinum electrode at the back of the probe. The deviation of $V_{\text {probe }}$ from 0 at $i_{\text {pump }}=0$ is attributed to thermoelectric voltages in the measuring circuit. $\partial V_{\text {probe }} / \partial i_{\text {pump }}$ was extracted as $6.4 \pm 0.2 \mu \Omega \mathrm{m}^{2}$. The standard deviation is about $3 \%$. The standard deviation will be lower at lower $T$ and lower $p_{\mathrm{O}_{2}}$ and higher at higher $T$ and higher $p_{\mathrm{O}_{2}}$.

The low standard deviations are a consequence of the oxygen pump which allows very precise measurement of the flux and $p_{\mathrm{O}}$ difference compared to traditional mass-balance experiments. ${ }^{11-13,30}$ Furthermore, the reliance on steady state allows very long sampling times of the measured voltages resulting in high precision on the individual measurement. The nonlinearities caused by the nonconstant $\sigma_{\mathrm{O}}$ of a membrane in a $\mu_{\mathrm{O}_{2}}$ gradient are avoided due to the very small $\mu_{\mathrm{O}_{2}}$ gradients. This has the added effect that the measured $G_{\mathrm{c}}$ and $r_{\mathrm{s}}$ values are indeed the values at $p_{\mathrm{O}_{2}}=p_{\mathrm{O}_{2}}^{\text {in }}$ and not integrated quantities over a large $p_{\mathrm{O}_{2}}$ interval.

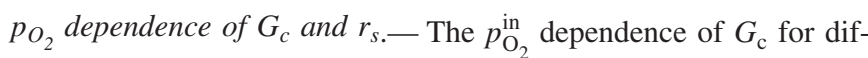
ferent temperatures is plotted in Fig. 10a. An increase in $G_{\mathrm{c}}$ is seen when $p_{\mathrm{O}_{2}}^{\text {in }}$ is lowered. $G_{\mathrm{c}}$ is proportional to $p_{\mathrm{O}_{2}}^{-0.114}$ at $T=1123 \mathrm{~K}$ and

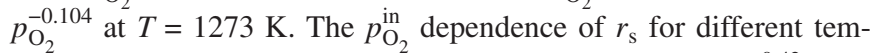
peratures is plotted in Fig. $10 \mathrm{~b} ; r_{\mathrm{s}}$ is proportional to $p_{\mathrm{O}_{2}}^{-0.42}$ at $T$ $=1123 \mathrm{~K}$ and $p_{\mathrm{O}_{2}}^{-0.65}$ at $T=1273 \mathrm{~K}$. The error bars show the precision of the measurements. It is remarkable that the precision of the measurement of $r_{\mathrm{s}}$ is reasonably small, even when measuring at $T$ $=1273 \mathrm{~K}$ and $p_{\mathrm{O}_{2}}=0.21 \mathrm{~atm}$. The origin of the scatter is discussed in the section on measurement reproducibility.

Temperature dependence of $G_{c}$ and $r_{s}-G_{\mathrm{c}}$ is plotted as function of $1 / T$ for air $\left(p_{\mathrm{O}_{2}}^{\text {in }}=20.9 \mathrm{kPa}\right)$ and an air $/ \mathrm{N}_{2}$ gas mixture $\left(p_{\mathrm{O}_{2}}^{\text {in }}\right.$ $=1.8 \mathrm{kPa})$ in Fig. 11a. $G_{\mathrm{c}}$ has an Arrhenius dependence with an activation energy of $E_{\mathrm{A}}=99 \mathrm{~kJ} / \mathrm{mol}$ for both gasses; $r_{\mathrm{s}}$ is plotted as function of $1 / T$ for flow gas with $p_{\mathrm{O}_{2}}^{\text {in }}=20.9$ and $1.8 \mathrm{kPa}$ in Fig. 11b. The surface reaction $\propto r_{\mathrm{S}}^{-1}$ has an Arrhenius dependence with an activation energy $E_{\mathrm{A}}$ of 172 and $95 \mathrm{~kJ} / \mathrm{mol}$ for each gas mixture, respectively.

The diffusion coefficient of $\mathrm{O}_{2}$ in a gas is proportional to $T^{3 / 2}{ }^{29}$ Oxygen concentration gradients in the gas phase will thus add terms

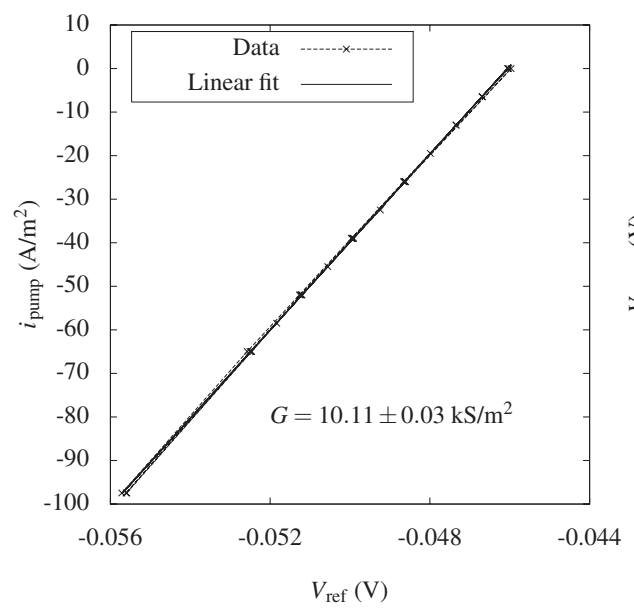

a)

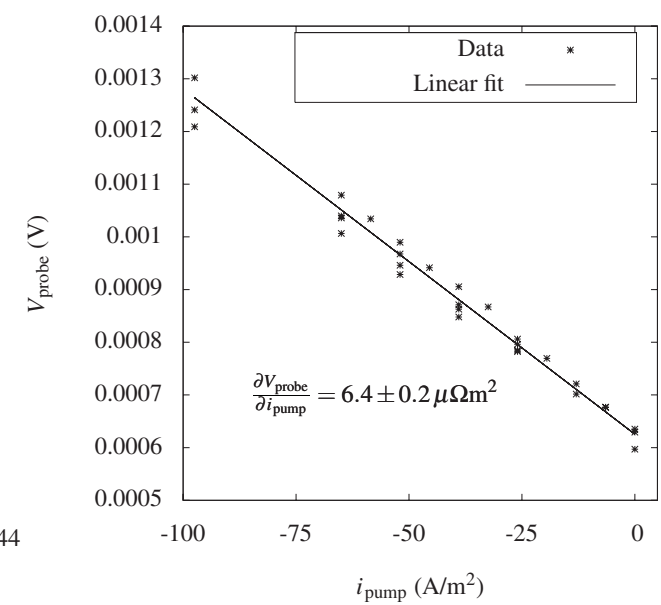

b)
Figure 9. (a) $i_{\text {pump }}$ as function of $V_{\text {ref. }} T$ $=1248 \mathrm{~K}$, gas $20 \%$ air $+80 \% \quad \mathrm{~N}_{2}$. (b) $V_{\text {probe }}$ as function of $i_{\text {pump. }} T=1248 \mathrm{~K}$, gas $20 \%$ air $+80 \% \mathrm{~N}_{2}$ 


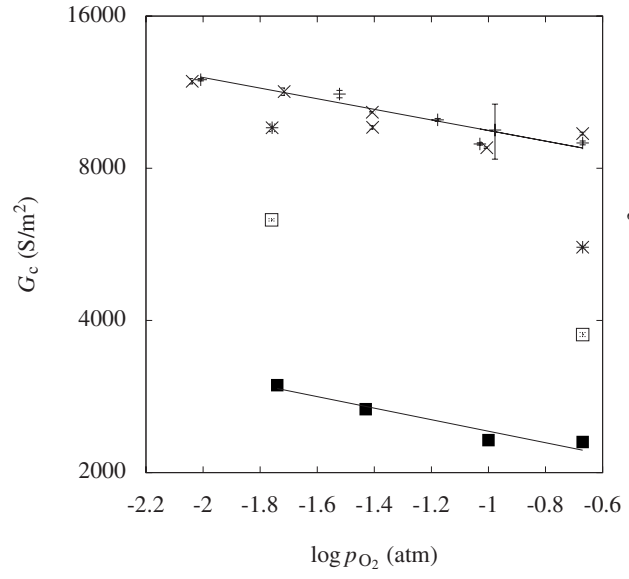

a)

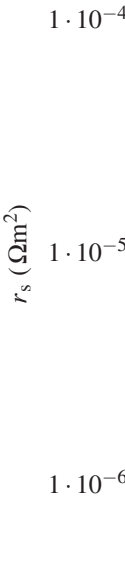

$\cdot 10^{-6}$

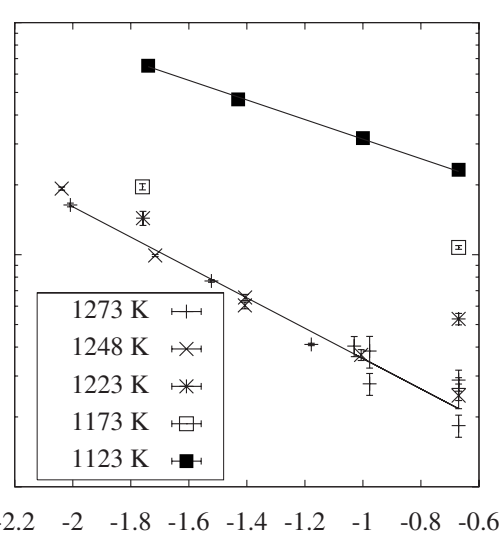

$\log p_{\mathrm{O}_{2}}(\mathrm{~atm})$
Figure 10. (a) $G_{\mathrm{c}}$ as function of $p_{\mathrm{O}_{2}}^{\text {in }}$ and temperature. (b) $r_{\mathrm{s}}$ as function of $p_{\mathrm{O}_{2}}^{\mathrm{in}^{2}}$ and temperature. (a) and (b) share legends. to $G_{\mathrm{c}}$ and $r_{\mathrm{s}}$ that will cause a deviation from activated behavior. As both $G_{\mathrm{c}}$ and $r_{\mathrm{s}}$ show no deviation from thermally activated behavior, we conclude that oxygen concentration gradients in the gas phase are not influencing our measurements.

Steady state model results. - The steady state model already described was used to extract $D_{\mathrm{v}}^{0}$ from the data of $G_{\mathrm{c}}$ and $r_{\mathrm{s}}$. This has been converted to $\sigma_{\mathrm{O}}$ and plotted in Fig. 12a. The fraction of $\Delta \mu_{\mathrm{O}_{2}}$ spent over the bulk part of the membrane, $f_{\text {bulk }}$, is plotted in Fig. 12b). As can be seen, the bulk transport limits the transport at high $p_{\mathrm{O}_{2}}$, while the surface exchange will dominate at low $p_{\mathrm{O}_{2}}$ as $r_{\mathrm{s}}$ is much larger at low $p_{\mathrm{O}_{2}}$. The large $r_{\mathrm{s}}$ at low $p_{\mathrm{O}_{2}}$ will at $\log p_{\mathrm{O}_{2}}(\mathrm{~atm})<-2.5$ begin to lower $G_{\mathrm{c}}$ (shown later).

The temperature dependence of $D_{\mathrm{v}}^{0}$ and $k_{\mathrm{O}}$ for air $\left(p_{\mathrm{O}_{2}}^{\text {in }}\right.$ $=20.9 \mathrm{kPa})$ and air $/ \mathrm{N}_{2}\left(p_{\mathrm{O}_{2}}^{\mathrm{in}}=1.8 \mathrm{kPa}\right)$ flow gas are shown in Fig. $13 \mathrm{a}$ and $\mathrm{b}$, respectively. The activation energies are 62 and

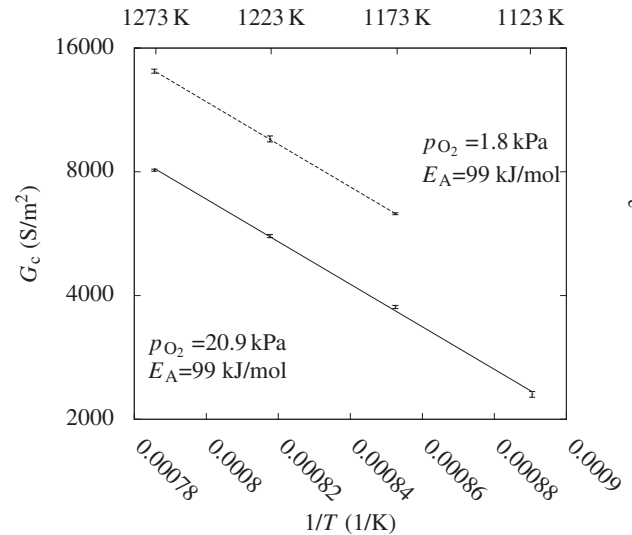

a)

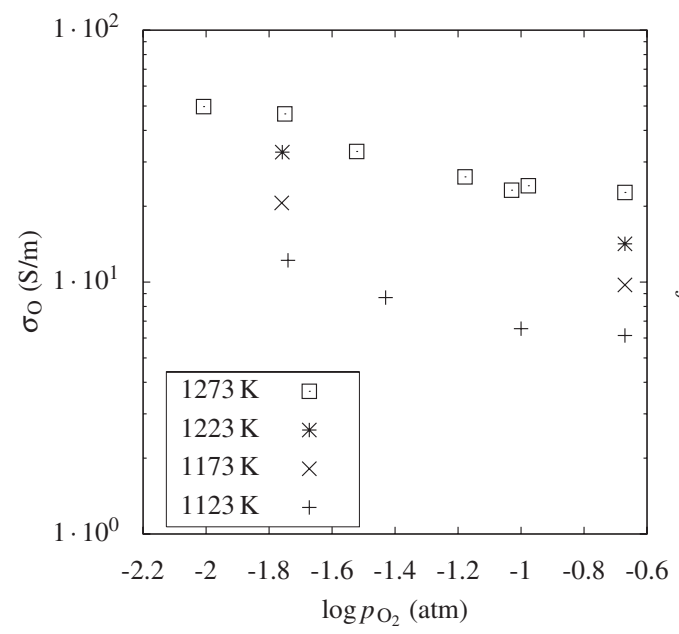

a)

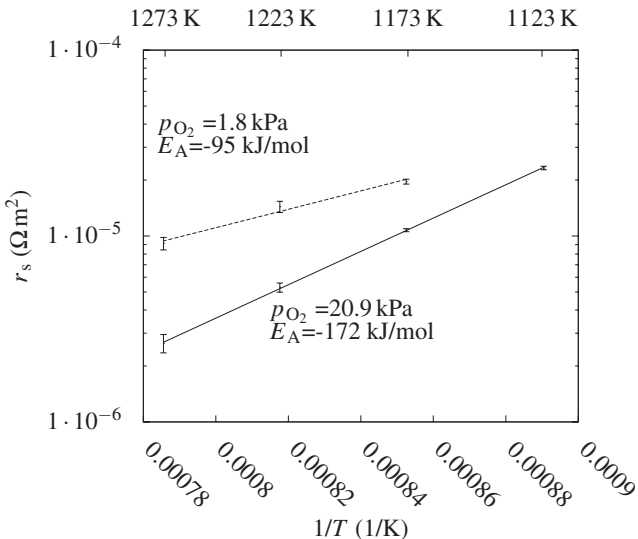

b)

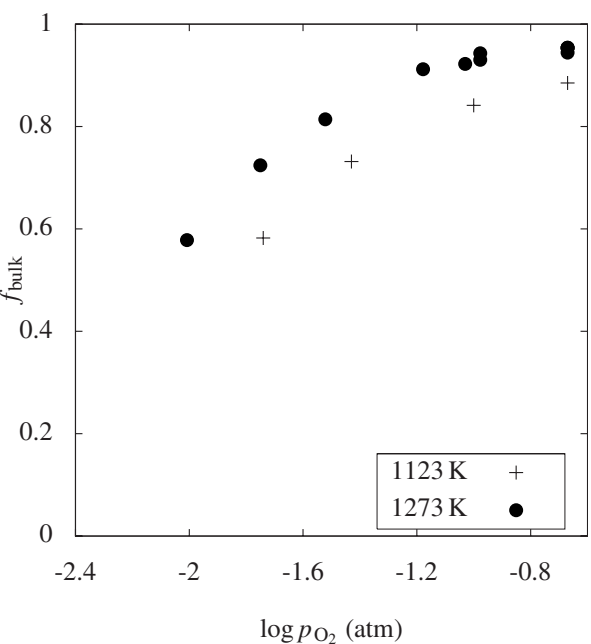

b)
Figure 11. (a) $G_{\mathrm{c}}$ as function of $1 / T$ plotted for air $\left(p_{\mathrm{O}_{2}}=20.9 \mathrm{kPa}\right)$ and air $/ \mathrm{N}_{2}$ $\left(p_{\mathrm{O}_{2}}^{\text {in }}=1.8 \mathrm{kPa}\right)$ flow gas. The activation energies are $99 \mathrm{~kJ} / \mathrm{mol}$ for both gas compositions. (b) $r_{\mathrm{s}}$ as function of $1 / T$ plotted for flow gas with $p_{\mathrm{O}_{2}}^{\text {in }}=20.9$ and $1.8 \mathrm{kPa}$. The activation energies for the surface reaction $\left(\propto r_{\mathrm{s}}^{-1}\right)$ are 172 and $95 \mathrm{~kJ} / \mathrm{mol}$, respectively.

Figure 12. (a) $\sigma_{O}$ as function of $T$ and $\log p_{\mathrm{O}_{2}}$. (b) $f_{\text {bulk }}$ as function of $T$ and $p_{\mathrm{O}_{2}}$. 


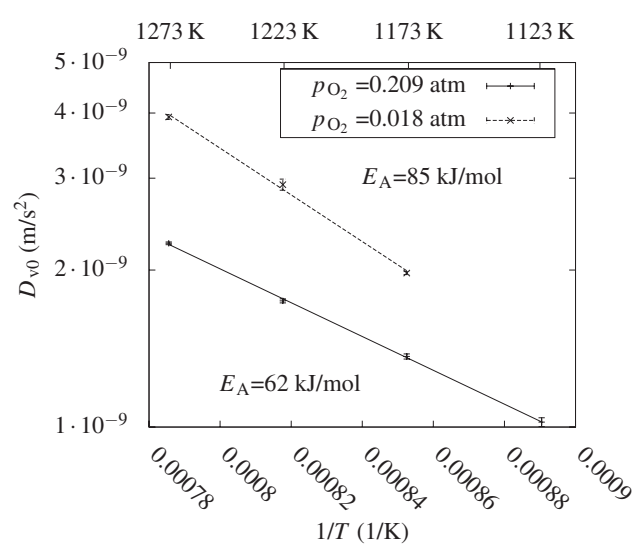

a)

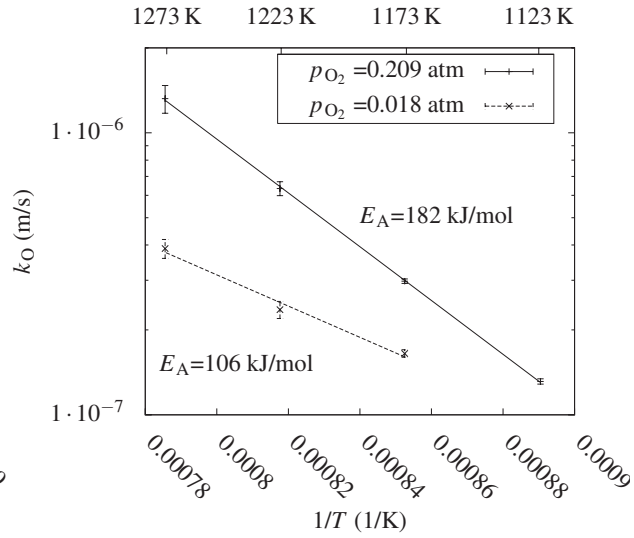

b)
Figure 13. (a) $D_{\mathrm{v}}^{0}$ as function of $1 / T$ plotted for air $\left(p_{\mathrm{O}_{2}}^{\text {in }}=20.9 \mathrm{kPa}\right)$ and air $/ \mathrm{N}_{2}$ $\left(p_{\mathrm{O}_{2}}^{\text {in }}=1.8 \mathrm{kPa}\right)$ flow gas. The activation energies are 62 and $85 \mathrm{~kJ} / \mathrm{mol}$, respectively. (b) $k_{\mathrm{O}}$ as function of $1 / T$ plotted for flow gases with $p_{\mathrm{O}_{2}}^{\text {in }}=20.9$ and $1.8 \mathrm{kPa}$. The activation energies for $k_{\mathrm{O}}$ are 182 and $106 \mathrm{~kJ} / \mathrm{mol}$, respectively.
$85 \mathrm{~kJ} / \mathrm{mol}$ for $D_{\mathrm{v}}^{0}$ in the two gases. For $k_{\mathrm{O}}$ they are 182 and $106 \mathrm{~kJ} / \mathrm{mol}$, respectively; $k_{\mathrm{O}}$ was calculated from $r_{\mathrm{s}}$ using the formulas in Fig. 3.

Transport parameters of LSCF measured using steady state measurements are summarized in Table I. Values of $\delta$ and $\gamma$ used in the computations are also provided.

Relaxation experiments.- Relaxation experiments were performed by making sudden changes of the composition, and thus $\mu_{\mathrm{O}_{2}}$, of the flow gas in the upper compartment, while keeping $i_{\text {pump }}=0$. An example of $\mu_{\mathrm{O}_{2}}$ in the membrane in the relaxation experiment shown in Fig. 15a at time, $t=120 \mathrm{~s}$, is shown in Fig. 14. Measured and calculated values of $V_{\text {probe }}$ and $V_{\text {ref }}$ for a sudden change in the gas composition $p_{\mathrm{O}_{2}}^{\text {in }}: 7.1 \mathrm{kPa} \rightarrow 3.2 \mathrm{kPa}$ at $T$ $=1273 \mathrm{~K}$ are plotted in Fig. 15a. Fitting parameter values of $D_{\mathrm{v}}^{0}$ $=2.9 \times 10^{-9}$ and $k_{\mathrm{O}}=5.6 \times 10^{-5} \mathrm{~m} / \mathrm{s}$ were used. At large times the calculated and measured values of $V_{\text {ref }}$ disagree. As the model uses many input data of finite precision $(\delta$, membrane dimensions, voltages), this disagreement is well within the expected precision. A contour plot of the summed square deviation ${ }^{31}$ of the measured and calculated values is given in Fig. 15b. SSD is normalized to the best fit $\left(\operatorname{SSD}_{\min }\right)$. The SSD is more sensitive to $D_{\mathrm{v}}^{0}$ than $k_{\mathrm{O}}$, and thus $D_{\mathrm{v}}^{0}$ is determined with higher precision than $k_{\mathrm{O}}$.

Measurement verification.- In the following we present measurements designed to rule out possible misinterpretations of the measured data.

Influence of corrections.- A few corrections were proposed earlier in the paper. These corrections are not necessarily specific to this setup, and will be equally relevant in, e.g., a conductivity relaxation experiment, where the perturbation of $p_{\mathrm{O}_{2}}^{\text {in }}$ can be considerable. To illustrate the impact of these corrections $G_{\mathrm{c}}$ and $r_{\mathrm{s}}$ (i.e., corrected values) are compared to $G$ and $V_{\text {probe }} / i_{\text {pump }}$ (i.e., uncorrected values) in Fig. 16a and b. The represent extrapolation towards lower $p_{\mathrm{O}_{2}}^{\text {in }}$ lines illustrating the steady state, model prediction values have been added. These lines were calculated using a weakly $p_{\mathrm{O}_{2}}$ dependent $D_{\mathrm{v}}^{0}$ and a $\partial V_{\text {probe }} / \partial i_{\text {pump }} \propto p_{\mathrm{O}_{2}}^{-0.68}$. The corrections to $G$ and $V_{\text {probe }} / i_{\text {pump }}$ in the measured $p_{\mathrm{O}_{2}}^{\text {in }}$ regime are less than $15 \%$. However, in accor- dance with Eq. 18 and 25 the extrapolations show that these corrections will increase as the $p_{\mathrm{O}_{2}}^{\text {in }}$ is reduced. Measurements in inert gas with $p_{\mathrm{O}_{2}}^{\text {in }}$ below $1 \mathrm{kPa}$ should therefore be interpreted with care. In regimes with high $r_{\mathrm{s}}$ (i.e., low temperature and low $p_{\mathrm{O}_{2}}^{\text {in }}$, it will be possible to conduct good measurements using low pumping currents; this reduces the corrections.

Influence of gas diffusion.- The diffusion of oxygen molecules in a gas is not infinitely fast; it is therefore important to test whether limitations of gas diffusion will develop gradients in the oxygen concentration, reducing the accuracy of the measurement. $i_{\text {pump }}$ is shown as a function of $V_{\text {ref }}$ for two experiments in Fig. 17a. One experiment is performed in a gas mixture of $90 \% \mathrm{He}+10 \%$ air, and the other in a gas mixture of $90 \% \mathrm{~N}_{2}+10 \%$ air. The diffusion coefficient of $\mathrm{O}_{2}$ in $\mathrm{He}$ is about four times larger than the diffusion coefficient of $\mathrm{O}_{2}$ in $\mathrm{N}_{2}$. Gradients in the gas above the membrane would thus be larger in the $90 \% \mathrm{~N}_{2}+10 \%$ air gas mixture than in $90 \% \mathrm{He}+10 \%$ air. Evidently $\mathrm{G}$ is independent of the gas diffusion coefficient of oxygen in the upper compartment. $V_{\text {probe }}$ is shown in Fig. $17 \mathrm{~b}$ as function of $i_{\text {pump }}$ at $T=1273 \mathrm{~K}$ in the same two experiments. It can be seen that $\partial V_{\text {probe }} / \partial i_{\text {pump }}$ is also independent of the gas diffusion coefficient.

The measurements shown in Fig. 9a and b are cautious measurements in the sense that oxygen is pumped out of the compartment below the membrane (negative values of $i_{\text {pump }}$ ) and the flux magnitude is kept low; this protects the membrane and glass seal from large mechanical pressure gradients. In the measurements in Fig. $17 \mathrm{a}$ and $\mathrm{b}$ the gradients and fluxes are much larger; this allows us to observe a deviation from the linear regime of $G$ in Fig. 17a. This deviation is only seen when pumping oxygen into the closed compartment. We believe that this is caused by leaks in the glass seal being forced open by oxygen overpressure at the membrane perimeter.

The $\partial V_{\text {probe }} / \partial i_{\text {pump }}$ shows a nonlinearity when pumping gas out of the closed compartment in Fig. 17b; this is attributed to a decrease of $p_{\mathrm{O}_{2}}^{\text {tip }}$ (i.e., the $p_{\mathrm{O}_{2}}$ in the gas beside the tip of the probe) and the corresponding increase in $r_{s}$. Both $G$ and $\partial V_{\text {probe }} / \partial i_{\text {pump }}$ are independent of pumping direction for small fluxes; this shows that the

Table I. Transport and stoichiometry parameters of LSCF in air, $k_{\text {chem }}$ is the chemical surface exchange coefficient, analogous to $D_{\text {chem }}$.

\begin{tabular}{|c|c|c|c|c|c|c|c|c|}
\hline $\begin{array}{c}T \\
(\mathrm{~K})\end{array}$ & $\begin{array}{c}D_{\mathrm{v}}^{0} \\
\left(\mathrm{~m}^{2} / \mathrm{s}\right)\end{array}$ & $\begin{array}{c}D_{\text {chem }} \\
\left(\mathrm{m}^{2} / \mathrm{s}\right)\end{array}$ & $\begin{array}{c}\sigma_{\mathrm{O}} \\
(\mathrm{S} / \mathrm{m})\end{array}$ & $\begin{array}{c}r_{\mathrm{s}} \\
\left(\Omega \stackrel{\mathrm{m}^{2}}{ }\right)\end{array}$ & $\begin{array}{l}k_{\text {chem }} \\
(\mathrm{m} / \mathrm{s})\end{array}$ & $\begin{array}{c}k_{\mathrm{O}} \\
(\mathrm{m} / \mathrm{s})\end{array}$ & $\delta$ & $\gamma$ \\
\hline 1123 & $1.02 \times 10^{-9}$ & $2.24 \times 10^{-9}$ & 6.14 & $2.32 \times 10^{-5}$ & $1.57 \times 10^{-5}$ & $1.31 \times 10^{-7}$ & $5.50 \times 10^{-2}$ & 119 \\
\hline 1173 & $1.37 \times 10^{-9}$ & $3.50 \times 10^{-9}$ & 9.74 & $1.08 \times 10^{-5}$ & $3.34 \times 10^{-5}$ & $2.98 \times 10^{-7}$ & $6.85 \times 10^{-2}$ & 112 \\
\hline 1223 & $1.75 \times 10^{-9}$ & $5.19 \times 10^{-9}$ & 14.2 & $5.28 \times 10^{-6}$ & $6.92 \times 10^{-5}$ & $6.34 \times 10^{-7}$ & $8.17 \times 10^{-2}$ & 109 \\
\hline 1273 & $2.25 \times 10^{-9}$ & $7.69 \times 10^{-9}$ & 20.2 & $2.65 \times 10^{-6}$ & $1.44 \times 10^{-4}$ & $1.32 \times 10^{-6}$ & $9.43 \times 10^{-2}$ & 109 \\
\hline
\end{tabular}




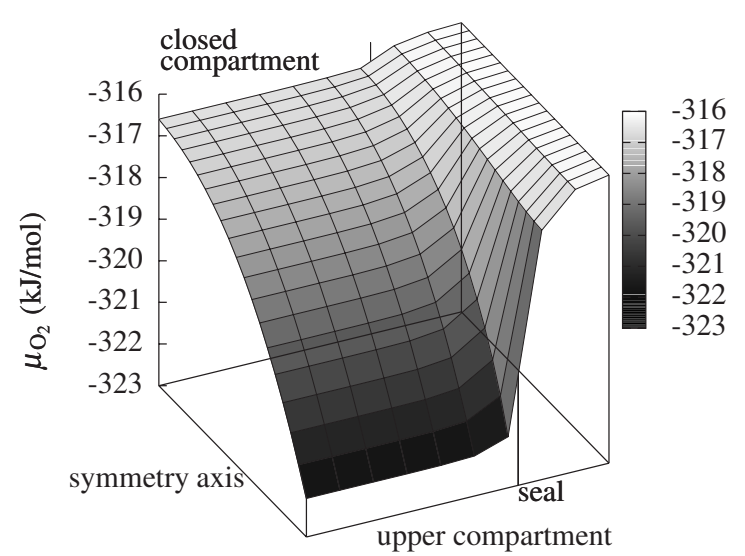

Figure 14. $\mu_{\mathrm{O}_{2}}$ in the membrane in the relaxation experiment shown in Fig. $15 \mathrm{a}$ at time, $t=120 \mathrm{~s}$. The total length along the symmetry axis is $2.253 \mathrm{~mm}$. The total length along the upper compartment edge is $10.15 \mathrm{~mm}$ (half the membrane diameter), with the aperture extending $7 \mathrm{~mm}$ from the symmetry axis, where the gold seal blocks the flux (see Fig. 6).

rate limiting step of gas entering and leaving the membrane surface is the same. This independence of the current direction is seen in all measurements for small fluxes.

$V_{\text {probe }}$ evaluation.- As mentioned earlier, $V_{\text {probe }}$ has several contributions apart from $V_{\text {surface. }}$. If electronic contact, but no ionic contact between the MIEC membrane and the probe exists, $V_{\text {probe }}$ will be the sum of these extra contributions only. In effect $V_{\text {probe }}$ will be mea- suring $p_{\mathrm{O}_{2}}^{\text {tip }}$, i.e., the $p_{\mathrm{O}_{2}}$ of the gas close to the contact point of the probe and membrane, and possibly some thermoelectric voltages. A measurement of $V_{\text {probe }}$ as function of the pumping current for a membrane of the LSCF derived MIEC material $\left(\mathrm{La}_{0.6} \mathrm{Sr}_{0.2} \mathrm{Ba}_{0.2}\right)_{0.99} \mathrm{Fe}_{0.8} \mathrm{Co}_{0.2} \mathrm{O}_{3-\delta}$ (LSB20CF) with a light load applied to the probe is compared to a measurement on LSCF with a heavy load applied to the probe, in Fig. 18. The $V_{\text {probe }} / i_{\text {pump }}$, was about 20 times less for the lightly loaded LSB20CF than for the heavily loaded LSCF (Fig. 18a). Except for the load on the probe and the sample composition, all other measurement parameters were equivalent. We interpret the low $V_{\text {probe }}$ as a sign of poor ionic contact to the membrane. In conclusion, with good ionic contact to the membrane, $V_{\text {grad }}$ is small compared to the contribution from $V_{\text {surface. }}$. Our recommendation is to apply a pressure of $10-100 \mathrm{MPa}$ to ensure ionic contact.

Measurement reproducibility.- While the precision error bars on the individual measurements in Fig. 10a and b, 11a, and b are smaller than the symbols used to mark the measurements, some scatter still exists. We believe that this is caused by slow relaxation of the membrane surface and microstructure. First, a series with varying $p_{\mathrm{O}_{2}}^{\text {in }}$ was run at $T=1273 \mathrm{~K}$. Neither $G_{c}$ or $r_{s}$ were reproducible. Another series was then run at $T=1248 \mathrm{~K}$. This series was reasonably reproducible. After a month of measurements a new series was recorded at $T=1273 \mathrm{~K}$. The values for $G_{c}$ or $r_{s}$ agreed reasonably with the last eight measurements of the first $T$ $=1273 \mathrm{~K}$ series. We conclude that more than one week of equilibration is needed before the membrane is stable. This is also seen

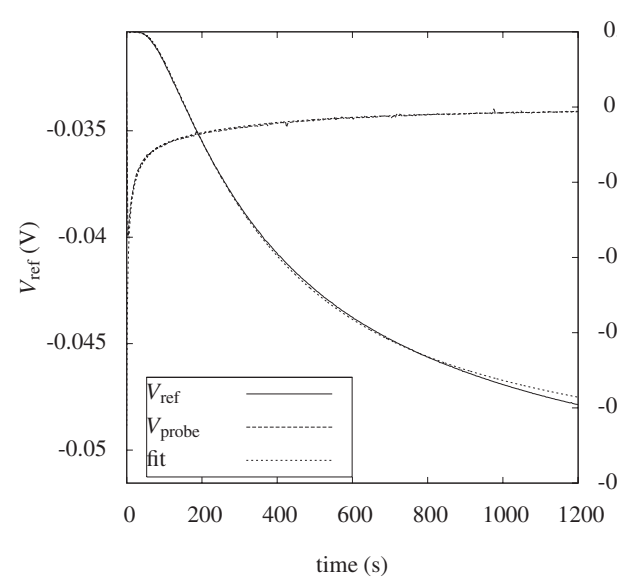

a)

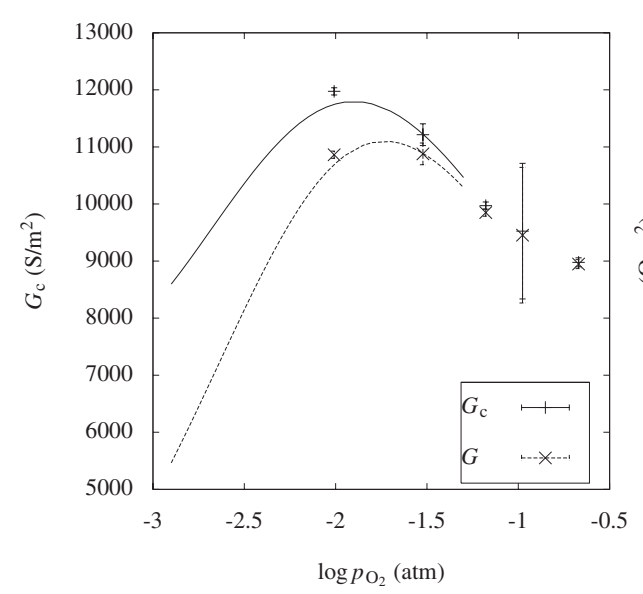

a)

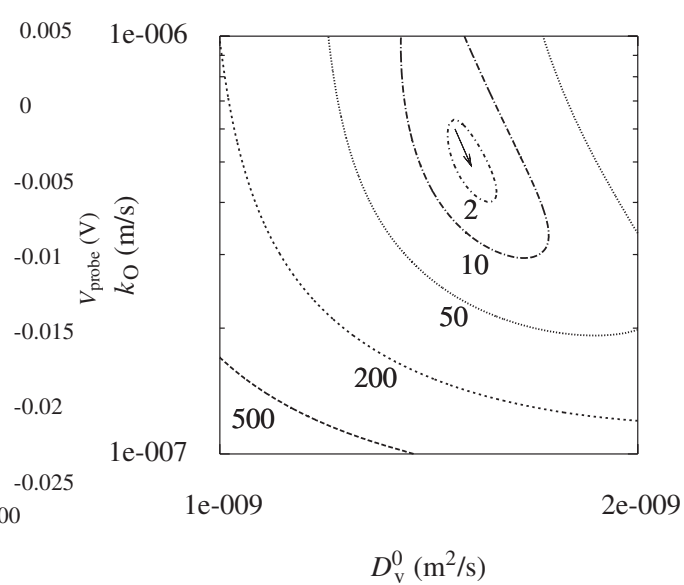

b)

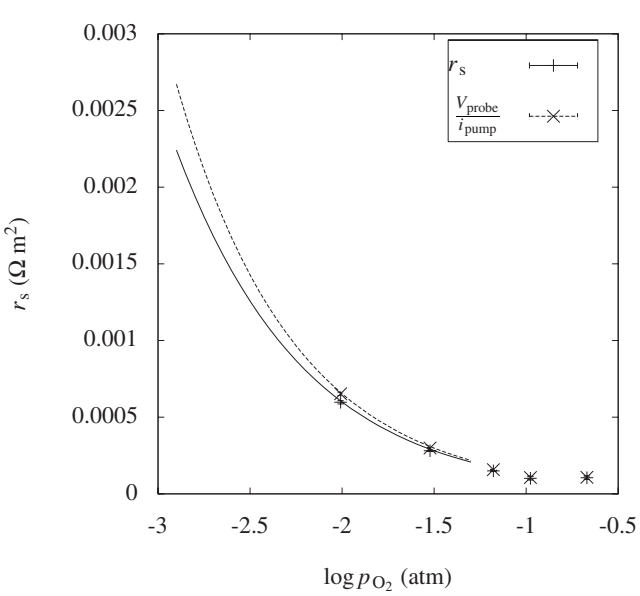

b)
Figure 15. (a) Measured $V_{\text {probe }}$ and $V_{\text {ref }}$ together with calculated values of $V_{\text {probe }}$ and $V_{\text {ref }}$ for a sudden gas composition change $p_{\mathrm{O}_{2}}^{\text {in }}: \quad 7.1 \mathrm{kPa} \rightarrow 3.2 \mathrm{kPa}$ at $T$ $=1273 \mathrm{~K} . \quad$ (b) Contour plot of $\mathrm{SSD} / \mathrm{SSD}_{\min }$ as function of $D_{\mathrm{v}}^{0}$ and $k_{\mathrm{O}}$.

Figure 16. (a) $G_{\mathrm{c}}$ and $G$ at $1273 \mathrm{~K}$ as a function of $\log p_{\mathrm{O}_{\mathrm{C}}}^{\text {in }}$. The lines are model predictions. (b) $r_{\mathrm{s}}$ and $\partial V_{\text {probe }} / \partial i_{\text {pump }}$ at $1273 \mathrm{~K}$ as a function of $\log p_{\mathrm{O}_{2}}$. The lines are model predictions. 


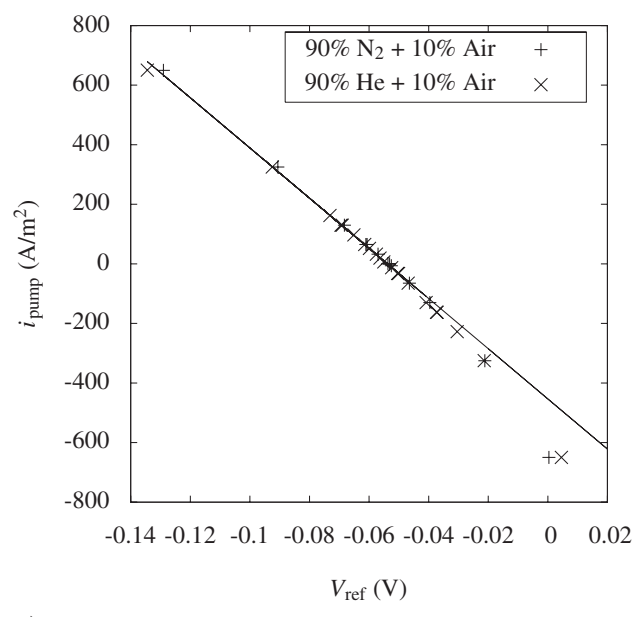

a)

with other membrane materials in this setup, and we attribute it to relaxation of the microstructure and surface, as well as possible cation diffusion.

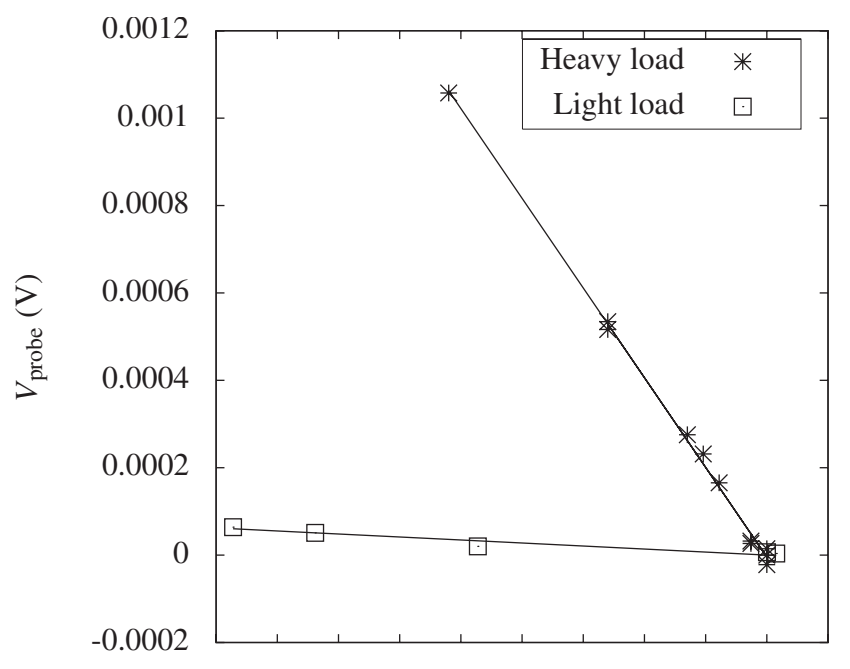

$-225-200-175-150-125-100-75 \quad-50 \quad-25 \quad 0 \quad 25$

$i_{\text {pump }}\left(\mathrm{A} / \mathrm{m}^{2}\right)$

Figure 18. Measurement of $V_{\text {probe }}$ at $p_{\mathrm{O}_{2}}=4 \mathrm{kPa}, \quad T=1273 \mathrm{~K}$ on $\left(\mathrm{La}_{0.6} \mathrm{Sr}_{0.4}\right)_{0.99} \mathrm{Co}_{0.2} \mathrm{Fe}_{0.8} \mathrm{O}_{3-\delta}$ (heavy load) and on $\left(\mathrm{La}_{0.6} \mathrm{Sr}_{0.2} \mathrm{Ba}_{0.2}\right)_{0.99} \mathrm{Fe}_{0.8} \mathrm{Co}_{0.2} \mathrm{O}_{3-\delta}$ (light load).

a)

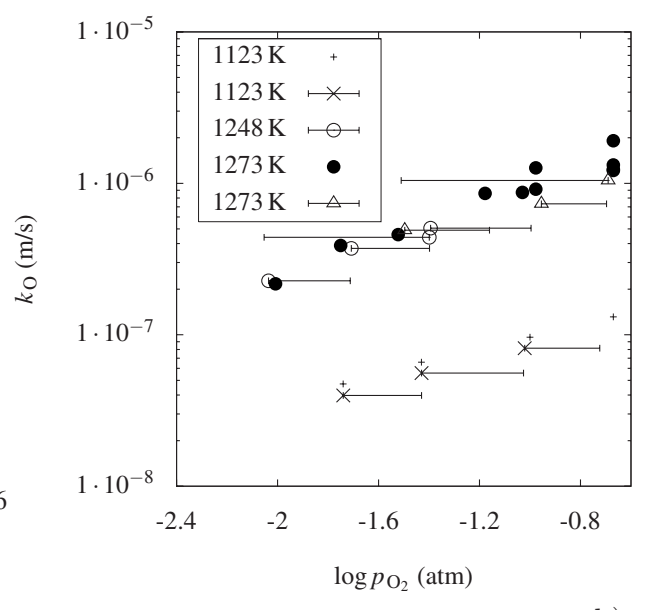

b)

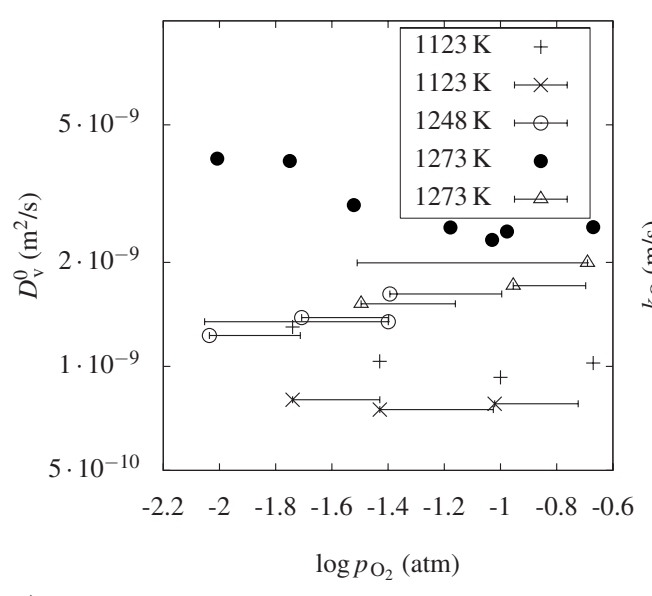

Figure 17. Measurements performed in a gas mixture of $90 \% \mathrm{He}+10 \%$ air (i.e., $2 \% \mathrm{O}_{2}+8 \% \mathrm{~N}_{2}$ ), and in $90 \% \mathrm{~N}_{2}+10 \%$ air. (a) $i_{\text {pump }}$ as function of $V_{\text {ref }}$ at $1273 \mathrm{~K}$. (b) $V_{\text {probe }}$ as function of $i_{\text {pump }}$ at $1273 \mathrm{~K}$.
Comparison of values from steady state and relaxation experiments. - An advantage of having both steady state and relaxation measurements performed in the same setup, is that comparison of the results from each measurement type can point out discrepancies in the modeling. $D_{\mathrm{v}}^{0}$ as deduced from the steady state measurements and the relaxation experiments are plotted in Fig. 19a. As mentioned earlier, $D_{\mathrm{v}}^{0}$ should not be directly dependent on $C_{\mathrm{v}}$, and should thus be a measure of the mobility of the vacancies. The values obtained using steady state measurements show an increase in $D_{\mathrm{v}}^{0}$ at low $p_{\mathrm{O}_{2}}$. The values for $D_{\mathrm{v}}^{0}$ obtained using relaxation experiments are constant when $p_{\mathrm{O}_{2}}^{\text {in }}$ is reduced at $T=1123 \mathrm{~K}$ and decrease slightly when $p_{\mathrm{O}_{2}}^{\text {in }}$ is reduced at $T=1248 \mathrm{~K}$ and $T=1273 \mathrm{~K}$. While the $D_{\mathrm{v}}^{0}$ values in air are very close and $p_{\mathrm{O}_{2}}^{\text {in }}$ dependencies of the steady state and relaxation values are not too different, the agreement is not complete. The conversion from $D_{\text {chem }}$ to $D_{\mathrm{v}}^{0}$ makes use of the thermodynamic factor $\gamma$ as well as $\delta$. Any error in these parameters will accumulate in $D_{\mathrm{v}}^{0}$. While the coulometric titration gives a high precision on $\gamma=\partial \ln p_{\mathrm{O}_{2}} / 2 \partial \ln c_{\mathrm{O}}$, the absolute value of $\delta$ is difficult to obtain as illustrated by the variation in the values reported in the literature (cf. Tai, ${ }^{32}$ Den Otter, ${ }^{33}$ or Stevenson ${ }^{12}$ ). Furthermore, $D_{\mathrm{v}}^{0}$ and $k_{\mathrm{O}}$ are linearly correlated in a steady state experiment, while the correlation is more complicated in the fit of a relaxation experiment. This could give a systematic difference in the results of steady state measurements and relaxation measurements.

The $k_{\mathrm{O}}$ values calculated from the steady state and the relaxation experiments are plotted in Fig. 19b. The steady state and relaxation values of $k_{\mathrm{O}}$ are in excellent agreement, if it is assumed that it is the
Figure 19. (a) $D_{\mathrm{v}}^{0}$ calculated from steady state and relaxation experiments. The marks connected to lines are relaxation experiments, where the marks signify the end $p_{\mathrm{O}_{2}}^{\text {in }}$ value of a relaxation and the bar spanning the $p_{\mathrm{O}_{2}}$ variation of the relaxation. (b) $k_{\mathrm{O}}$ calculated from the steady state and the relaxation experiments. 
end $p_{\mathrm{O}_{2}}^{\text {in }}$ that determines $k_{\mathrm{O}}$ in the relaxation. This is expected, as the

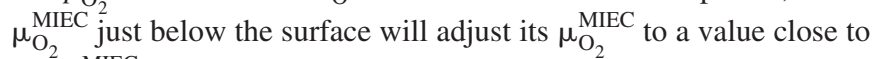
the $\mu_{\mathrm{O}_{2}}^{\text {MIEC }}$ of the flow gas during the first tenth of the fitted relaxation time; $k_{\mathrm{O}}$ is proportional to to $p_{\mathrm{O}_{2}}^{0.41}$ at $T=1123 \mathrm{~K}$ and $p_{\mathrm{O}_{2}}^{0.52}$ at $T=1273 \mathrm{~K}$. It is worth noting that the precision of the measurement of the steady state values of $k_{\mathrm{O}}$ is on the order of the symbol size or less, even when measuring at $T=1273 \mathrm{~K}$ and $p_{\mathrm{O}_{2}}=0.21 \mathrm{~atm}$.

The increase in $D_{\mathrm{v}}^{0}$ with lower $p_{\mathrm{O}_{2}}^{\text {in }}$ in the steady state measurements could be caused by misinterpretation of the measured data. At low $p_{\mathrm{O}_{2}}$ surface oxygen exchange processes become more important in determining the oxygen transport (about $45 \%$ of the $\mu_{\mathrm{O}_{2}}$ difference is found at the surfaces at $p_{\mathrm{O}_{2}}^{\text {in }}=1 \mathrm{kPa}$ and $T=1123 \mathrm{~K}$ ), and the increase in $D_{\mathrm{v}}^{0}$ could be related to an overestimation of $r_{s}$. As the $\left(V_{\text {probe }} / i_{\text {pump }}\right)$ plots used to determine $r_{s}$ are close to linear at all measured $p_{\mathrm{O}_{2}}^{\mathrm{in}}$ values, terms causing an overestimation not accounted for must have the same linearity.

One error term with such a linearity could be caused by the probe penetrating deep into the membrane and probing $\mu_{\mathrm{O}_{2}}$ some distance into the bulk. Another term could come from the probe blocking the flux and altering the $\mu_{\mathrm{O}_{2}}$ profile through the membrane, resulting in an enhanced $V_{\text {probe }}$. To investigate these possibilities, each of the relaxation measurements were fitted again, but this time with the cone depth as a fitting parameter. No common cone probe depth was, however, found for the relaxations.

Thermovoltages have also been dismissed as an error term. While heat from the oxidation reaction will change the temperature at the probe tip, the enthalpy of oxidation should only be weakly temperature dependent and as the thermopower of the CG10 probe increases with temperature, ${ }^{34}$ the thermovoltage would not experience the decrease of $r_{s}$ with temperature seen in Fig. 11b. Furthermore, localized ohmic heating in the membrane will scale with $\left(i_{\text {pump }}\right)^{2}$ in contrast with the linear relations seen in Fig. 9b. Finally the Seebeck coefficient is less than $20 \mu \mathrm{V} / \mathrm{K}$.

\section{Conclusion}

A setup combining an oxygen pump with an electrolyte probe was demonstrated. From this setup the $\mu_{\mathrm{O}_{2}}$ difference across a LSCF membrane and across the LSCF membrane surface could be determined from the voltage across a pair of reference electrodes on the oxygen pump and from the voltage across the electrolyte probe in contact with the membrane surface. During steady state the voltages had a linear dependence on the oxygen flux. The area specific conductance, $G_{\mathrm{c}}$ (a measure of the permeability of the membrane), and the surface resistance, $r_{\mathrm{s}}$, could thus be extracted. $G_{\mathrm{c}}$ and $r_{\mathrm{s}}$ were found to be independent of the flux direction, showing that the rate limiting step of the oxygen exchange reaction on the surface is the same when oxygen is incorporated into the membrane and when it is released from the membrane. From $G_{\mathrm{c}}$ and $r_{\mathrm{s}}$ a model was used to extract values of the ionic conductivity, $\sigma_{\mathrm{O}}$ and the concentration independent vacancy diffusion factor $D_{\mathrm{v}}^{0}$. Excellent precision was achieved using small pertubations, illustrating the advantages of $(i)$ measuring at steady state (with very large sampling times), (ii) direct electronic measurement of the oxygen flux, (iii) direct electronic measurement of the $\mu_{\mathrm{O}_{2}}$ difference across the membrane surface and (iv) direct electronic measurement of the total $\mu_{\mathrm{O}_{2}}$ difference across the membrane. Furthermore, precise determination of $r_{\mathrm{s}}$ was not limited to low temperature and low $p_{\mathrm{O}_{2}}$, where $r_{\mathrm{s}}$ is normally dominating the transport, but could also be recorded at high temperature and $p_{\mathrm{O}_{2}}$, where it is usually too small to determine accurately. A model based on Ficks law of diffusion was used to fit the measured voltages after stepwise gas composition changes and thus extract $D_{\mathrm{v}}^{0}$ and $k_{\mathrm{O}}$. The values extracted from steady state and relaxation measurements were reasonably consistent. article.

Risø National Laboratory assisted in meeting the publication costs of this

$\begin{array}{lc}\text { Table A-I. Value of } \boldsymbol{n}_{\boldsymbol{i}} \text { to be used in Eq. A-1 and A-2. } \\ n_{1} & 1.06778 \\ n_{2} & 3.50042 \\ n_{3} & 0.166961 \times 10^{-7} \\ n_{4} & 1.01258 \\ n_{5} & 0.944365 \\ n_{6} & 2242.45 \mathrm{~K} \\ n_{7} & 11,580.4 \mathrm{~K}\end{array}$

Appendix A

Chemical Potential of Oxygen in the Gas Phase

The following equations and values are all taken from Oxygen, IUPAC International Tables of the Fluid State 9 in Ref. 24.

The entropy, $S^{\text {id }}(T)$, and the enthalpy, $H^{\text {id }}(T)$, of an ideal gas at the temperature, $T$, and the pressure $P_{A}=1 \mathrm{~atm}$ can be found from the equations below

$$
\begin{aligned}
S^{\mathrm{id}}\left(T, P_{A}\right)= & R\left[-\frac{2 n_{1}}{3}\left(\frac{T}{K}\right)^{-3 / 2}+n_{2} \ln \left(\frac{T}{K}\right)+\frac{n_{3}}{2}\left(\frac{T}{K}\right)^{2}+n_{4}\left(\frac{u \mathrm{e}^{u}}{\mathrm{e}^{u}-1}-\ln \left(\mathrm{e}^{u}-1\right)\right)\right. \\
& \left.+n_{5}\left(\frac{\frac{2}{3} \varphi \mathrm{e}^{-\eta}}{1+\frac{2}{3} \mathrm{e}^{-\eta}}+\ln \left(1+\frac{2}{3} \mathrm{e}^{-\eta}\right)\right)\right]_{298.15 \mathrm{~K}}^{T}+205.146 \mathrm{~J} \mathrm{~mol}^{-1} \mathrm{~K}^{-1}
\end{aligned}
$$

$$
\begin{aligned}
H^{\mathrm{id}}\left(T, P_{A}\right)= & R(1(K))\left[-2 \mathrm{n}_{1}\left(\frac{\mathrm{T}}{\mathrm{K}}\right)^{-1 / 2}+\mathrm{n}_{2} \frac{\mathrm{T}}{\mathrm{K}}+\frac{\mathrm{n}_{3}}{3}\left(\frac{\mathrm{T}}{\mathrm{K}}\right)^{3}+n_{4} \frac{u\left(\frac{T}{K}\right)}{\mathrm{e}^{\mathrm{u}}-1}\right. \\
& \left.-\mathrm{n}_{5} \frac{\eta\left(\frac{T}{K}\right)}{1+\frac{2}{3} \mathrm{e}^{-\eta}}\right]_{298.15 \mathrm{~K}}^{T}
\end{aligned}
$$

In the above equations $u=n_{6} / T$ and $\eta=n_{7} / T$ and the values of $n_{1}, n_{2}, n_{3}, n_{4}, n_{5}, n_{6}$, and $n_{7}$ can be found in Table A-I.

Using these formulas the entropy and the enthalpy is determined at a temperature $T$. The term $205.146 \mathrm{~J} \mathrm{~mol}^{-1} \mathrm{~K}^{-1}$ (in Eq. A-1) originates from the entropy difference between the state of the ideal crystal at $0 \mathrm{~K}$ and that of the ideal gas at $(298.15 \mathrm{~K}$, $0.1 \mathrm{MPa}$ ).

The chemical potential of oxygen in the gas phase is then calculated as

$$
\mu_{\mathrm{O}_{2}}=\mu_{\mathrm{O}_{2}}^{\Theta}+R T \ln \left(\frac{P}{P_{A}}\right)
$$

where

$$
\mu_{\mathrm{O}_{2}}^{\Theta}=H^{\mathrm{id}}\left(T, P_{A}\right)-T S^{\mathrm{id}}\left(T, P_{A}\right)
$$

\section{Appendix B}

Derivation of the Average Driving Force above the Membrane

When a molar flow of oxygen, $J_{\mathrm{O}_{2}}\left[\mathrm{~mol} \mathrm{~s}^{-1}\right]$, passes through the membrane it will change the $p_{\mathrm{O}_{2}}$ in the upper compartment

$$
p_{\mathrm{O}_{2}}=p_{\mathrm{O}_{2}}^{\text {in }}+\frac{J_{\mathrm{O}_{2}}}{J_{\mathrm{N}_{2} / \mathrm{O}_{2}}+J_{\mathrm{O}_{2}}} \approx p_{\mathrm{O}_{2}}^{\text {in }}+\frac{J_{\mathrm{O}_{2}} R T_{\Phi_{\mathrm{f}}}}{P \Phi_{\mathrm{f}}}
$$

where $J_{\mathrm{N}_{2} / \mathrm{O}_{2}}$ is the molar flow of the nitrogen/air mixture, led from the external gas supply, through the tubes, into the upper compartment. $P$ is the absolute pressure, $\Phi_{\mathrm{f}}$ is the volume flow, and $T_{\Phi_{f}}$ is the $T$ where volume flow is measured.

The gas flow enters the upper compartment above the center of the membrane and moves towards the periphery. The $p_{\mathrm{O}_{2}}$ above the center of the membrane will thus be close to the $p_{\mathrm{O}_{2}}$ above the center of the membrane will thus be close to the $p_{\mathrm{O}_{2}}$ of the gas entering the chamber, while the $p_{\mathrm{O}_{2}}$ of the gas at the periphery will be close to the gas leaving the chamber. $V^{\text {upper }}$ will thus depend on the distance from the center of the membrane, $r$

$$
V^{\text {upper }}(r)=\frac{R T}{4 F} \ln \left(\frac{p_{\mathrm{O}_{2}}^{\text {in }}+\frac{J_{\mathrm{O}_{2}}(r) R T_{\Phi_{\mathrm{f}}}}{P \Phi_{\mathrm{f}}}}{p_{\mathrm{O}_{2}}^{\text {ref }}}\right)
$$

where $J_{\mathrm{O}_{2}}(r)$ is the amount of oxygen passing through the membrane inside a circle with radius $r . J_{\mathrm{O}_{2}}(r)$ is a fraction of $J_{\mathrm{O}_{2}}$ 


$$
J_{\mathrm{O}_{2}}(r)=\int_{0}^{r} J_{\mathrm{O}_{2}} \frac{2 \pi r^{\prime}}{\pi r_{0}} d r^{\prime}=\frac{r^{2}}{r_{0}^{2}} J_{\mathrm{O}_{2}}
$$

where $r_{0}$ is the total exposed membrane surface. The average $V^{\text {upper }}$ on the surface will be

$$
V^{\text {upper }}=\frac{1}{\pi r_{0}^{2}} \int_{0}^{r_{0}} V^{\text {upper }}(r) 2 \pi r d r
$$

which leads to Eq. 18 .

\section{References}

1. The CRC Handbook of Solid State Electrochemistry, P. Gellings and H. Bouwmeester, Editors, CRC, Boca Raton, FL (1997).

2. S. J. Skinner and J. A. Kilner, Mater. Today, 6, 30 (2003).

3. P. V. Hendriksen, P. H. Larsen, M. Mogensen, F. W. Poulsen, and K. Wiik, Catal. Today, 56, 283 (2000).

4. H. J. M. Bouwmeester, Catal. Today, 82, 141 (2003).

5. I. Yasuda and T. Hikita, J. Electrochem. Soc., 141, 1268 (1994).

6. J. ten Elshof, M. Lankhorst, and H. Bouwmeester, Solid State Ionics, 99, 15 (1997).

7. J. Lane and J. Kilner, Solid State Ionics, 136-137, 997 (2000).

8. M. Søgaard, P. V. Hendriksen, M. Mogensen, F. W. Poulsen, and E. Skou, Solid State Ionics, 177, 3285 (2006).

9. S. Carter, A. Selcuk, R. J. Chater, J. Kajda, J. A. Kilner, and B. C. H. Steele, Solid State Ionics, 53-56, 597 (1992).

10. S. J. Benson, R. J. Chater, and J. A. Kilner, Proc. Electrochem. Soc. PV 97-24, p. 596 (1999).

11. J. ten Elshof, H. Bouwmeester, and H. Verweij, Solid State Ionics, 81, 97 (1995).

12. J. W. Stevenson, T. Armstrong, R. Carnheim, L. Pederson, and W. Weber, J. Electrochem. Soc., 143, 2722 (1996).
13. J. Lane, S. Benson, D. Waller, and J. Kilner, Solid State Ionics, 121, 201 (1999).

14. M. Lankhorst, Ph.D.Thesis, Universiteit Twente, Enschede (1997).

15. M. Søgaard, P. V. Hendriksen, and F. W. Poulsen, in Proceedings of the 26th Ris International Symposium on Materials Science, 1, 355 (2005).

16. Y. L. Yang, A. J. Jacobsen, C. L. Chen, G. P. Luo, K. D. Ross, and C. W. Chu, Appl. Phys. Lett., 79, 776 (2001).

17. B. Zachau-Christiansen, T. Jacobsen, and S. Skaarup, Solid State Ionics, 86-88, 725 (1996).

18. A. Belzner, T. M. Gür, and R. A. Huggins, Solid State Ionics, 40-41, 535 (1990).

19. S. Diethelm, Ph.D.Thesis, Lausanne EPFL (2001).

20. D.-K. Lee and H.-I. Yoo, J. Electrochem. Soc., 147, 2835 (2000).

21. J. Fouletier, P. Fabry, and M. Kleitz, J. Electrochem. Soc., 123, 204 (1976)

22. H.-D. Wiemhöfer, H.-G. Bremes, U. Nigge, and W. Zipprich, Solid State Ionics, 150, 63 (2002)

23. L. A. Chick, G. L. Maupin, L. R. Pederson, D. E. McCready, and J. L. Bates, Mater. Res. Soc. Symp. Proc., 249, 159 (1992).

24. W. Wagner, K. M. de Reuck, Oxygen, IUPAC International Tables of the Fluid State 9.

25. J. Maier, Solid State Ionics, 112, 197 (1998).

26. R. Tilley, Principles and Applications of Chemical Defects, Stanley Thornes Ltd., Cheltenham, U.K. (1998).

27. C. Wagner, Prog. Solid State Chem., 10, 3 (1975).

28. J. Crank, The Mathematics of Diffusion, Oxford University Press, Oxford (1975).

29. R. C. Reid, J. M. Prausnitz, and B. E. Polling, The Properties of Gases and Liquids, McGraw-Hill, New York (1987).

30. M. Søgaard, P. V. Hendriksen, and M. Mogensen, J. Solid State Chem., 180, 1489 (2007).

31. P. Bevington and D. Robinson, Data Reduction and Error Analysis for the Physical Sciences, 3rd ed., McGraw-Hill, New York (2003).

32. L.-W. Tai, M. Nasrallah, H. U. Anderson, D. Sparlin, and S. Sehlin, Solid State Ionics, 76, 273 (1995).

33. M. den Otter, Ph.D. Thesis, Universiteit Twente, Enschede (2000).

34. H.-T. Lim and A. V. Virkar, J. Power Sources, 161, 676 (2006). 